Article

\title{
Fuzzy Ensemble of Multi-Criteria Decision Making Methods for Heating Energy Transition in Danish Households
}

\author{
Qianyun Wen ${ }^{1}$, Qiyao Yan ${ }^{2}$, Junjie $Q u^{1}$ and Yang Liu ${ }^{1, * \mathbb{D}}$ \\ 1 Department of Management and Engineering, Linköping University, SE-581 83 Linköping, Sweden; \\ qianyun.wen@liu.se (Q.W.); junqu078@student.liu.se (J.Q.) \\ 2 Transportation Engineering College, Dalian Maritime University, Dalian 116026, China; \\ 2220181572@dlmu.edu.cn \\ * Correspondence: yang.liu@liu.se
}

Citation: Wen, Q.; Yan, Q.; Qu, J.; Liu, Y. Fuzzy Ensemble of Multi-Criteria Decision Making Methods for Heating Energy Transition in Danish Households. Mathematics 2021, 9 , 2420. https://doi.org/10.3390/ math9192420

Academic Editors: Víctor Yepes and José Moreno-Jiménez

Received: 31 August 2021

Accepted: 23 September 2021

Published: 29 September 2021

Publisher's Note: MDPI stays neutral with regard to jurisdictional claims in published maps and institutional affiliations.

Copyright: (c) 2021 by the authors. Licensee MDPI, Basel, Switzerland. This article is an open access article distributed under the terms and conditions of the Creative Commons Attribution (CC BY) license (https:/ / creativecommons.org/licenses/by/ $4.0 /)$.

\begin{abstract}
More than 110 countries, including 500 cities worldwide, have set the goal of reaching carbon neutrality. Heating contributes to most of the residential energy consumption and carbon emissions. The green energy transition of fossil-based heating systems is needed to reach the emission goals. However, heating systems vary in energy source, heating technology, equipment location, and these complexities make it challenging for households to compare heating systems and make decisions. Hence, a decision support tool that provides a generalized ranking of individual heating alternatives is proposed for households as decision makers to identify the optimal choice. This paper presents an analysis of 13 heating alternatives and 19 quantitative criteria in technological, environmental, and financial aspects, combines ideal solution-based multi-criteria decision making with 6 weighting methods and 4 normalization methods, and introduces ensemble learning with a fuzzy membership function derived from Cauchy distribution to finalize the ultimate ranking. The robustness of the proposed method is verified by three sensitive analyses from different aspects. Air-to-water heat pump, solar heating and direct district heating are the top three rankings in the final result under Danish national average data. A framework is designed to guide decision makers to apply this ranking guideline with their practical, feasible situations.
\end{abstract}

Keywords: multi-criteria decision making; individual heating; fuzzy ensemble; energy transition

\section{Introduction}

\subsection{Motivation}

Climate change is currently considered one of the most significant global crises. Limiting global warming to $1.5^{\circ} \mathrm{C}$ requires rapid and deep transitions in energy, land, and urban infrastructures, as well as industrial systems [1]. Governments are seriously taking this into the agenda. More than 110 countries, including 500 cities worldwide, have set the goal of reaching carbon neutrality [2]. In addition, $78 \%$ of European cities have greenhouse gas (GHG) mitigation targets [3]. Challenges have been raised in the long-term planning and decision making of the energy transition for municipalities in order to reach the emission goals [4]. Especially in the Danish context of our research, the municipality has a key role in the national transition to a fossil-free society because strategic energy planning in Denmark is clearly defined as a responsibility of the municipalities.

Heating is a key part of the energy transition. Heating for buildings accounts for nearly $25 \%$ of global energy end-use, in which fossil-fuel heating is responsible for $8 \%$ of global $\mathrm{CO}_{2}$ emissions [5]. The Danish Climate Agreement for Energy and Industry 2020 [6] emphasizes that oil and gas boilers must be phased out and replaced with green district heating or electric heat pumps to achieve green heating. The agreement [7] allocates DKK 2.3 billion to support the replacements for the next 10 years, including subsidies for heat pumps and free disconnection of gas networks. Hence, there is an increasing need for decision supports to identify the optimal heating choice, especially the green transition 
path for those using natural gas and oil as heating sources, in order to achieve the climate commitments of the local governments.

Heating systems differ in energy source, heat technology, equipment location, heat carrier, transfer mechanism and heat requirement in the heated spaces [8,9]. Energy sources are a major factor impacting the environment [10]; they are divided into fossil fuels, including oil, gas and coal, and renewables, including biomass, solar, geothermal, air, water, and waste [9]. Besides the traditional single energy source, research for combinations of multiple energy sources has increased, such as hybrid source heat pumps [11] and district heating [12]. Each category has developed heating technology, including fireplaces, stoves, boilers, heaters, heat pumps, solar thermal collectors, and cogeneration. Heating systems can also be classified as local, central and district heating systems by equipment location [8]. Therefore, many different combinations can be made for a heating system; the complexity would increase the difficulty of making an optimal decision, especially for regular households.

Thus, how one can choose an optimal heating system becomes the next challenge. There are mainly three general aspects that need to be considered when one makes a heating choice: financial costs, technical considerations, and climate friendliness. Financial costs cover the entire usage span, such as costs for purchasing equipment, installation, maintenance and periodical consumption. Technical considerations usually include heating efficiency, lifespan, difficulties compared with currently installed old technologies, and other technical problems, such as noise level. Climate change calls more and more attention to the environment not only by governments, but also by residents. A recent survey conducted by Evida, which is a national natural gas supplier in Denmark, shows that over $44 \%$ of individuals in Denmark believe climate-friendly energy technology would be one out of three most important features to be considered if they need to buy a new heating technology, ranking in the third position among a total of 12 choices (the top two are both financial costs related) [13]. However, considering too many indicators, especially those that are sometimes contradictory regarding financial cost and climate friendliness, could be a significant challenge. Hence, a decision support instrument, such as multi-criteria decision making (MCDM), that is especially effective in facing such a circumstance [14] becomes necessary.

\subsection{Novelties}

Many have used MCDM in evaluating and selecting optimal renewable and nonrenewable energy sources [15]. However, little of the scientific literature has focused on household-level energy technology (only 14 studies assessed renewable energy technologies in households through MCDM within the last 30 years), although its significant potential for decarbonization is acknowledged [16]. None of the studies has compared more than seven technology alternatives, which is insufficient for individuals to make a full comparison of all potential alternatives. Only one of them has focused on Denmark.

This research proposes a decision support tool that provides a generalized ranking of individual heating alternatives for decision makers to identify the optimal choice. The solution is based on an analysis of 13 heating alternatives and 19 quantitative criteria in technological, environmental, and financial aspects. The resultant ranking from a single MCDM could be easily altered [17]. Thus, an approach with more stable and consistent results is proposed. It combines ideal solution-based MCDM with six weighting methods and four normalization methods and introduces ensemble learning with a fuzzy membership function derived from Cauchy distribution to finalize the ultimate ranking. Here, ideal means the two selected evaluation methods are ideal solutions based on ranking, and the decision makers aim for the ideal solutions. In reality, the ideal solution cannot be reached, but an optimal solution close to the ideal one can be selected.

This study contributes both theoretically and practically. The theoretical contribution lies in the proposed general framework to support objective decision making by optimizing the rankings from multiple ideal solution-based MCDMs through a fuzzy ensemble 
approach to achieve the optimal combination and decrease the variance in ranking results from a single MCDM. The practical contribution lies in providing a full, detailed, yet generalized ranking of heating alternatives. It could be used as a guide for both residences and municipalities for the heating energy transition. Moreover, the proposed tool can be easily and broadly applied to other fields that face similar problems with multiple alternatives and criteria to be considered during decision making processes.

The analysis structure of this research is shown in Figure 1. The rest of the article is organized as follows. Section 2 explains the conceptual framework of the methodology and the detailed methods used. Section 3 present the results by applying the methods with real data. Then, a discussion is presented in Section 4. Conclusions with limitations and future works are given in Section 5 .

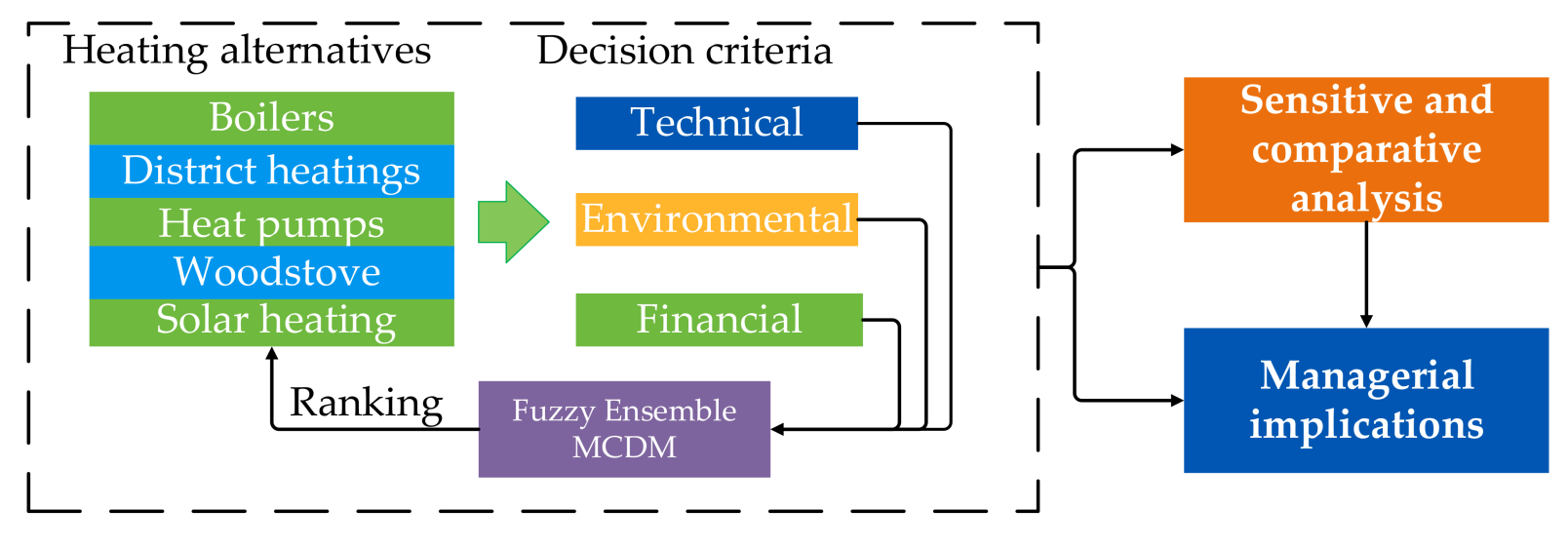

Figure 1. Research structure.

\section{Methods}

Multi-criteria analysis is needed, considering sustainability's multi-dimensional nature, energy systems' complexity [18], and variation of households' situations. Thus, numerous studies have applied MCDM methods in energy sectors regarding sustainability analysis. Ref. [19] applied MCDM for the development of renewable energy systems on islands. Ref. [20] introduced the framework of dividing the MCDM application methodological process into five steps. It starts from alternatives selection, criteria selection, weighting and evaluation, followed by final treatment as the end, including sensitivity, reliability analysis and Monte Carlo simulation. Ref. [21] showed that recent surveys are focusing on MCDM for sustainability and renewable energy support.

Although there is much development of MCDM toward application in energy sectors, certain limitations of this approach have been identified as well. Ref. [22] argued the complexity of energy planning issues, regarding the presence of different approaches. The different results of all approaches with uncertain final decision values showed a need for appropriate quantitative techniques to deal with imprecise information and evaluate the real effect of uncertainties on the final results, such as ranking the alternatives. Ref. [17] argued that results from MCDM could be easily altered because of its alternative nature in the underlying assumptions, such as criterion weights. Thus, groups of alternative rankings are generated through distinct normalization, weighting, and ranking methods to stabilize the final outcomes.

Ensemble learning is an interpretation for the wisdom of the crowd; the ensemble methodology can be explained from the tendency of human nature to collect various opinions and information and weigh and combine them in order to make a more complicated and reasonable decision, where it is believed that the aggregation of a group of ideas is better than choosing only one from all [23]. Ensemble learning is introduced to the approach to aggregate the numerous groups of primary rankings, eliminating the limitations of MCDM mentioned above. 
The decision support methodology in this paper is shown in Figure 2 and tested in the Danish heating energy transition problem. It starts with the selected alternatives and criteria according to the defined problem. Then, the selected alternatives and criteria data, as a format of matrix $M_{i j}$, are normalized with methods of MinMax, Max, Vector, and Enhanced [24], and weighted with methods of Mean, Standard deviation, Entropy, Angle, Gini, and Criteria importance through inter-criteria (CRITIC) [25]. The generated objective weights $w_{j}$ and normalized matrix $\bar{M}_{i j}$ are calculated and combined with the evaluation methods, where Vise Kriterijumska Optimizacija Kompromisno Resenje (VIKOR) and Technique for Order Preference by Similarity to an Ideal Solution (TOPSIS) are used to generate $m$ ranking data sets $R_{m \times i}$. Next, the final ranking $\bar{R}_{i}$ is aggregated by an ensemble approach, using fuzzy membership function derived from Cauchy and logarithm function.

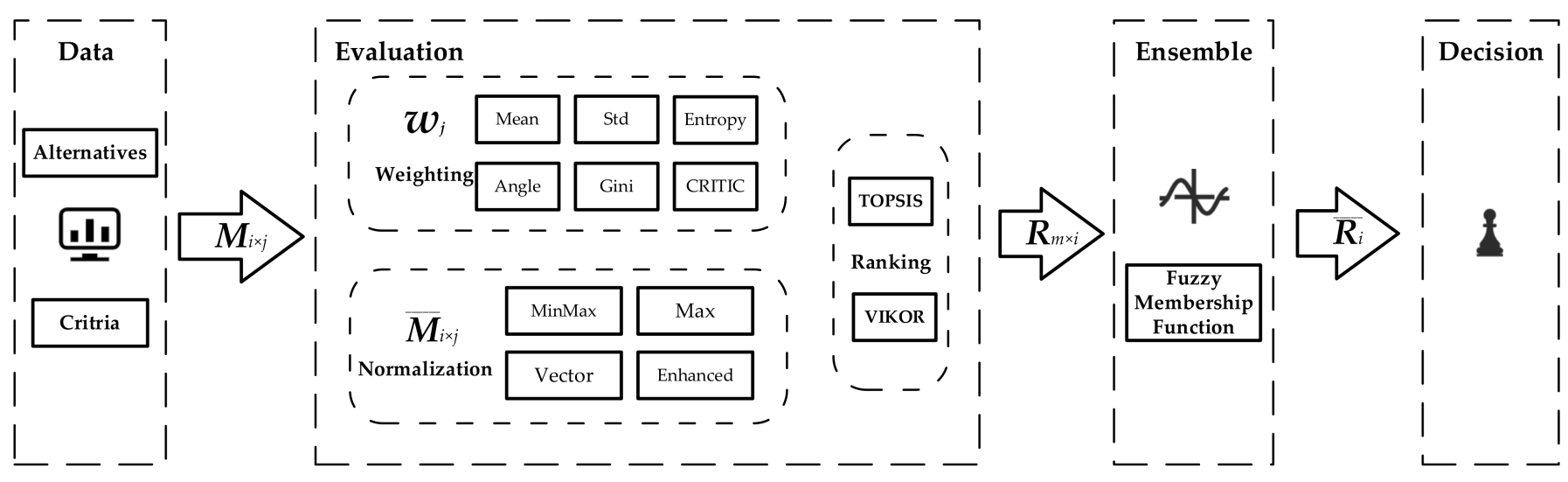

Figure 2. Decision support methodology.

\subsection{Multi-Criteria Decision Making}

MCDM has rapidly developed a large number of objective and subjective methods in recent years. Technique for Order Preference by Similarity to an Ideal Solution (TOPSIS) has become one of the most popular approaches in the field of solving energy sector issues due to its relatively rational logic [16]. It selects the alternative with the shortest distance from the positive ideal solution and the longest distance from the negative ideal solution [20]. Even though TOPSIS can completely use allocated information, it does not contain the consideration toward correlations between attributes, and a strong deviation of indicators in the ideal solution might influence the results significantly [26]. Vise Kriterijumska Optimizacija Kompromisno Resenje (VIKOR) has the advantage of maximizing "group utility" for the "majority" and minimizing individual regret for the "opponent" [27]. Through a proximity analysis of the ideal solution, VIKOR can develop a ranking with several, usually conflicting alternative criteria [20]. However, VIKOR requires initial weights and quantitative information to work with [26]. This paper focuses on these two ideal solution-based methods with the combination of objective weighting and normalization. With the combination of these methods, the approach can bypass some disadvantages of both TOPSIS and VIKOR.

Table 1 shows the equations used for weighting and normalization methods with the corresponding notations defined in Table 2. The normalization equation has separated for a different target. For criteria that target maximization (max), the larger the value of that criterion is, the better it is. For criteria that target minimization (min), the smaller the criterion's value is, the better it is. 
Table 1. Equations for weighting and normalization.

\begin{tabular}{|c|c|}
\hline Weighting Method & Equation \\
\hline Mean & $w_{j}=\frac{1}{n}$ \\
\hline Std & $w_{j}=\frac{\sigma\left(M_{j}\right)}{\sum_{j=1}^{J} \sigma\left(M_{j}\right)}$ \\
\hline Entropy & $d_{j}=1+\frac{1}{\ln \left(\frac{x_{i j}}{\sum_{i=1}^{J} x_{i j}}\right)} \sum_{j=1}^{J}\left(\frac{x_{i j}}{\sum_{i=1}^{J} x_{i j}} \ln \left(\frac{x_{i j}}{\sum_{i=1}^{J} x_{i j}}\right)\right), w_{j}=\frac{d_{j}}{\sum_{j=1}^{J} d_{j}}$ \\
\hline CRITIC & $C_{j}=\sum_{i=1}^{I}\left(1-r_{i j}\right) \sqrt{\frac{\sum_{i=1}^{I}\left(x_{i j}-\frac{1}{n} \sum_{i=1}^{n} x_{i j}\right)}{n-1}}, w_{j}=\frac{C_{j}}{\sum_{j=1}^{J} C_{j}}$ \\
\hline Angle & $u_{j}=\arccos \left(\frac{\sum_{i=1}^{I} \overline{x_{i j}}}{\left\|\overline{M_{i}}\right\|_{2}\left\|\overline{M_{j}}\right\|_{2}}\right), w_{j}=\frac{u_{j}}{\sum_{j=1}^{J} u_{j}}$ \\
\hline Gini & $v_{i}=\sum_{j=1}^{J} \frac{\left|x_{i j}-M_{j}\right|}{2 n^{2} \frac{\sum_{i=1}^{I} x_{i j}}{n}}, w_{j}=\frac{v_{j}}{\sum_{j=1}^{J} v_{j}}$ \\
\hline Normalization Method & Target: $\max$ \\
\hline MinMax & $\bar{x}_{i j}=\frac{\max \left(M_{i}\right)-x_{i j}}{\max \left(M_{i}\right)-\min \left(M_{i}\right)}$ \\
\hline $\begin{array}{l}\text { Max } \\
\text { Vector }\end{array}$ & $\begin{array}{c}\bar{x}_{i j}=\frac{x_{i j}}{\max \left(M_{i}\right)} \\
\bar{x}_{i j}=\frac{x_{i j}}{\left\|M_{i}\right\|_{2}}\end{array}$ \\
\hline Enhanced & $\bar{x}_{i j}=1-\frac{\max \left(M_{i}\right)-x_{i j}}{\sum_{j=1}^{J} \max \left(M_{i}\right)-x_{i j}}$ \\
\hline
\end{tabular}

Table 2. Nomenclature.

\begin{tabular}{cc}
\hline Notation & Definition \\
\hline$I$ & Alternatives set \\
$J$ & Criteria set \\
$w_{j}$ & $j_{t h}$ criterion weight \\
$M_{i}$ & $i_{\text {th }}$ alternative's score vector \\
$M_{j}$ & $j_{\text {th }}$ criterion's score vector \\
$x_{i j}$ & $i_{\text {th }}$ alternative $j_{\text {th }}$ criterion score \\
$\sigma(\cdot)$ & Standard deviation of a dataset \\
$\bar{x}_{i j}$ & $x_{i j}$ after normalization \\
$n$ & Criteria number \\
$r_{i j}$ & Correlation coefficient \\
$\bar{M}_{i}$ & $M_{i}$ after normalization \\
$\bar{M}_{j}$ & $M_{j}$ after normalization \\
\hline
\end{tabular}

With the weighting matrix and normalization matrix, TOPSIS calculates the distance to the positive ideal solution and negative ideal solution by Equation (1) and measures the ranking value by Equation (2) for each alternative in descending order. VIKOR calculates the ranking values by Equations (3) and (4) and measures them by ascending order.

$$
\begin{gathered}
D_{i}^{+}=\sqrt{\sum_{j=1}^{m}\left(\max \left(w_{j} \bar{M}_{j}\right)-\bar{M}_{i j}\right)^{2}}, D_{i}^{-}=\sqrt{\sum_{j=1}^{m}\left(\min \left(w_{j} \bar{M}_{j}\right)-\bar{M}_{i j}\right)^{2}} \\
C_{i}=\frac{D_{i}^{-}}{D_{i}^{+}+D_{i}^{-}} \\
S_{i}=\sum w_{j}\left(\frac{\max \left(\bar{M}_{i j}\right)-\bar{x}_{i j}}{\max \left(\bar{M}_{i}\right)-\min \left(\bar{M}_{j}\right)}\right), R_{i}=\max \left\{w_{j}\left(\frac{\max \left(\bar{M}_{j}\right)-\bar{x}_{i j}}{\max \left(\bar{M}_{j}\right)-\min \left(\bar{M}_{j}\right)}\right)\right\}
\end{gathered}
$$




$$
Q_{i}=v \frac{S_{i}-\min (S)}{\max (S)-\min (S)}+(1-v) \frac{R_{i}-\min (R)}{\max (R)-\min (R)}
$$

\subsection{Ensemble}

An ensemble learning methodology originally from machine learning is adopted to generate a stronger ranking by utilizing relatively weaker ranking sets from each MCDM. Fuzzy membership distribution with Cauchy distribution is introduced [28].

By assuming (a) when ranking $=1$ and membership $=0.9$, (b) when ranking $=6$, and membership $=0.1$, and (c) when ranking $=13$ and membership $=0, f(x)$ can be calculated through Cauchy distribution as shown in Equations (5) and (6).

$$
\begin{gathered}
f u z z y(x)= \begin{cases}1-\left[1+a(x-b)^{-2}\right]^{-1}, & 1 \leq x \leq 6 \\
1-c \ln x+d, & 6 \leq x \leq 13\end{cases} \\
a=\frac{225}{64}, b=\frac{3}{8}, c=\frac{1}{10 \ln \frac{13}{6}}, d=\frac{\ln 13}{10 \ln \frac{13}{6}}-1
\end{gathered}
$$

All the MCDM rankings are summarized to the final ranking through a fuzzy transition. Equation (7) shows the final ranking calculation, where $\operatorname{rank}(A, S)$ means $A^{\prime}$ s ranking in set $S$, and $s_{i j}$ means $i$ th alternative and $j$ th ranking.

$$
\bar{R}(i)=\operatorname{rank}\left(\sum_{j}^{j=J} f u z z y\left(s_{i j}\right), \sum_{i}^{i=I} \sum_{j}^{j=J} f u z z y\left(s_{i j}\right)\right)
$$

\subsection{Pseudocode}

The pseudocode of the proposed fuzzy ensemble MCDM is shown in Algorithm 1 to present the steps in the programming processes. The methodology is tested by an empirical heating ranking problem with real data in the next section.

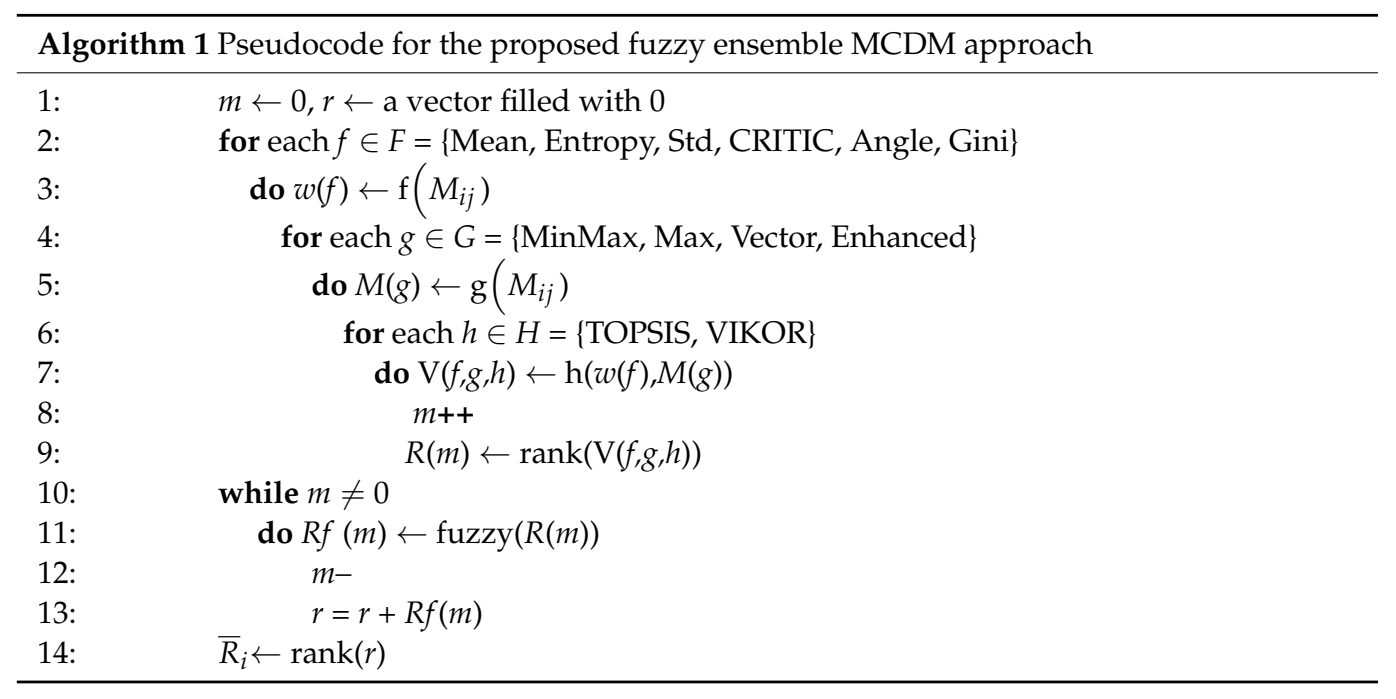

\section{Empirical Results}

In this section, the proposed aggregated methodology is applied to the problem of building energy transition at the household level. In order to support the decision making process for each household, a comprehensive and objective ranking list of heating solution alternatives is generated. The application is mainly divided into two steps. Firstly, a matrix combining alternatives and criteria is processed through normalization, weighting, and ranking methods to generate enough ranking list sets. Then, ensemble methods are applied to a large number of primary ranking list sets in order to finalize the ultimate ranking. Considering the stability problem of MCDM, sensitivity analyses are used. 


\subsection{Alternatives}

The heating alternatives are selected based on the principle of representative technologies and available mature products in the Danish market and international individuals to support a generic comparison [29]. Both the possible currently installed heating technologies and available green heating technologies are listed, providing a clear comparison for the decision makers. A total of 13 heating technology alternatives are investigated, as shown in Table 3.

Table 3. Lists of 13 heating alternatives.

\begin{tabular}{cc}
\hline Heating Alternatives & ID \\
\hline Oil boiler & $\mathrm{H} 1$ \\
Gas boiler & $\mathrm{H} 2$ \\
Biomass boiler (auto) & $\mathrm{H} 3$ \\
Biomass boiler (manual) & $\mathrm{H} 4$ \\
District heating (indirect) & $\mathrm{H} 5$ \\
District heating (direct) & $\mathrm{H} 6$ \\
Heat pump (air to water) & $\mathrm{H} 7$ \\
Heat pump (air to water, low-price product) & $\mathrm{H} 8$ \\
Heat pump (ground source) & $\mathrm{H} 9$ \\
Heat pump (gas-hybrid) & $\mathrm{H} 10$ \\
Heat pump (air-to-air) & $\mathrm{H} 11$ \\
Woodstove & $\mathrm{H} 12$ \\
Solar heating & $\mathrm{H} 13$ \\
\hline
\end{tabular}

\subsubsection{Boilers}

The fuel types can categorize heating with boilers into oil boilers, gas boilers and biomass boilers. Oil boilers often use domestic fuel oil, which is similar to diesel. Although the technology is simple but reliable and highly efficient, the price of fuel oil is unpredictable and volatile, so its cost could be potentially expensive. Gas boilers use the fuel of gas, such as natural gas, biomethane, etc. Gas boilers have advantages of high efficiency, low investment cost, and low gas fuel price while emitting fewer greenhouse gases and pollution, compared with other fossil fuel boilers. The transport of gas fuels could be easy and less costly than the transport of oil fuels, but it requires pre-construction of the gas grid. Biomass boilers mainly have two types: automatic and manual stoking. For both kinds of biomass boilers, the fuels are usually wood pellets. The manual biomass boilers can also use other sizes of wood depending on their stoking room.

Biomass boilers with automatic stoking have a relatively high investment cost. However, if the transition is from oil boilers, the extra investment is quite low because it often only requires changing a burner for biomass. Biomass boilers with manual stoking are a simple and robust technology. The pellets fuel is exempted from tax, which provides competitive costs regarding other alternatives with fossil fuels. However, automatic biomass boilers usually require a large space, sometimes an extra boiler room. Manual biomass boilers require effort in feeding and cleaning the boilers. Additionally, for both biomass boilers, the storage of fuels also requires extra room.

\subsubsection{District Heating}

District heating is usually a system with pipes that distributes the thermal heat of hot water to end-users for heating. It can be categorized into two types: direct and indirect district heating. The difference is based on whether a substation is placed between the central heat plants and end users.

For district heating as a whole, it is promoted by many regions, due to its numerous advantages. Its low maintenance costs, low noise level, and no local pollution are due to its separate central heat plants. Compared to other individual heating solutions, the central heat plants of district heating can use various energy sources. It makes the usage of surplus heat from industries and power production possible, and it can achieve economies of 
scale, which leads to the low cost of fuels and storage of fuels. Compared to direct district heating, indirect district heating has a substation usually near the end users, requiring extra equipment investment and electricity costs. However, district heating alternatives are limited if the pre-construction of central heat plants and branch pipes are not complete. Other disadvantages are mainly for energy suppliers and municipalities. There are costs for maintenance and operation, considering the long transport of hot water and heat loss during the transport in the network. Furthermore, the loss will increase with decreasing population density in rural areas.

\subsubsection{Heat Pumps}

The heat pump is a system that draws heat from a heat source and transfers the heat to the endpoints through a closed process. The working process is similar to refrigerators but with reversed energy transfer direction. There are two major heat pump technologies: compression-type heat pumps powered by electricity and absorption-type heat pumps powered by thermal energy. Considering that the data used are collected from Denmark, where absorption-type heat pumps are rarely used, the presented heat pumps are of the compression type in this paper. Within electric compression heat pumps, technologies can be categorized by their energy sources and transfer process as air-to-water, ground-source, air-to-air, and gas-hybrid heat pumps.

The major advantage of heat pumps is that they can provide more heat than the electricity they consume. Air-to-water heat pumps draw heat from ambient air and convert the heat to endpoints by a water-based heat distribution system. Easy installation and low noise level are advantages of air-to-water heat pumps. The normal model usually requires large equipment investment, but the annual cost is significantly lower. Regarding this large investment, there are cheaper models. However, the cheap models usually generate more noise and last shorter lifespans. Ground-source heat pumps, also called brine-to-water heat pumps, absorb heat from the ground and convert the heat to space heat or hot water. Due to its underground heat collector, usually, there is no noise, and it is quite reliable during its lifespan. However, it requires a large equipment investment and a large underground area for installation. Air-to-air heat pumps draw heat from ambient air and convert it through an air-heat distribution system. The equipment investment is relatively low, and the installation is quite simple. However, it cannot supply heat to a large area, so it is usually combined with other alternatives. A gas-hybrid heat pump usually refers to a hybrid heating solution combining an electric heat pump and a condensing gas boiler. The most common type of combination in Denmark is the combination of an air-to-water heat pump and a gas boiler. The solution is offered because it can bypass some of the disadvantages of gas boilers and electric heat pumps. It can significantly reduce emissions due to the low share of heat generated by gas boilers. The gas boilers are mostly used when the temperature difference between the heat source of the heat pumps and delivered heat is large, which greatly decreases the heat pumps' efficiency. Because both systems do not need to function fully to supply the target heat, the lifespans of both systems are usually longer than when functioning alone. The disadvantage is obvious that the maintenance work is doubled, due to having two systems.

\subsubsection{Woodstove}

The woodstove is a traditional heater that contains an enclosed room to heat the space nearby. Usually, firewood is the combustion source. Woodstoves can be independent of electricity supply, but they require effort in manual operation. The price of wood fuel varies very little, and some households might have access to wood at a low cost.

\subsubsection{Solar Heating}

Using solar energy is usually done through transferring heat liquid to heat water and domestic spaces. Heat liquid is heated from the solar collectors covering the roof. Solar energy is well known as an energy source with unlimited amounts and without any 
pollution. However, its disadvantages are obvious as well: there is a high installation cost for its collectors and a mismatch between the heating demand and solar energy availability.

\subsection{Criteria}

Since the decision makers are households all over Denmark with different locations, the currently installed heating technologies, financial situations, application of regulations and personal preferences, and feasible heating sets considered by each decision maker vary greatly. Specifically, whether a house is located in a current district heating or a future district heating area decides its feasibility in choosing the district heating. The functioning condition, remaining lifespan, and possibilities of currently installed heating combined with additional heating also influence the choices of decision makers. The financial situation will have strong influence in considering technologies with high investment. Some decision makers could face regulations that constrain solar panels or other external units' (e.g., heat pumps) installation, due to architectural concerns. Personal preferences, such as enjoying the warmness of a woodstove, can also largely influence the choice of decision makers. Therefore, the designed framework separates the above individual indicators for the decision makers' own subjective consideration and keeps the ideal solution-based ensemble heating ranking objective. Hence, all criteria selected are quantitative indicators regarding technical, environmental, and financial data. Since there are both full-year heating and supplement-only heating alternatives, the expected share of the space heating demand and hot tap water demand can be covered by each alternative. Table 4 summarizes all selected criteria with their measurement, ID, data source and max or min ideal target.

Table 4. Criteria sets for heating alternatives assessment.

\begin{tabular}{|c|c|c|c|c|c|}
\hline Dimension & Criteria & Measurement & ID & Target & Source \\
\hline \multirow{6}{*}{ Technical } & Expected covered space heating demand & share & $\mathrm{T} 1$ & $\max$ & [29] \\
\hline & Expected covered hot tap water demand & share & $\mathrm{T} 2$ & $\max$ & [29] \\
\hline & Annual average heat efficiency & $\begin{array}{l}\text { net heat/fuel } \\
\text { consumption }\end{array}$ & T3 & $\max$ & [29] \\
\hline & Technical economic lifespan & years & $\mathrm{T} 4$ & $\max$ & [29] \\
\hline & Time spends on manual maintenance & hours/y & $\mathrm{T} 5$ & $\min$ & [29] \\
\hline & Noise & $\mathrm{dB}$ & T6 & $\min$ & {$[29,30]$} \\
\hline \multirow{6}{*}{ Environmental } & $\mathrm{SO}_{2}$ emission & $\mathrm{g} / \mathrm{GJ}$ & E1 & $\min$ & {$[29,31,32]$} \\
\hline & $\mathrm{PM}_{2 \cdot 5}$ emission & $\mathrm{g} / \mathrm{GJ}$ & E2 & $\min$ & {$[29,31,32]$} \\
\hline & $\mathrm{NO}_{\mathrm{x}}$ emission & $\mathrm{g} / \mathrm{GJ}$ & E3 & $\min$ & {$[29,31,32]$} \\
\hline & $\mathrm{CH}_{4}$ emission & $\mathrm{g} / \mathrm{GJ}$ & E4 & $\min$ & {$[29,31,32]$} \\
\hline & $\mathrm{N}_{2} \mathrm{O}$ emission & $\mathrm{g} / \mathrm{GJ}$ & E5 & $\min$ & {$[29,31,32]$} \\
\hline & $\mathrm{CO}_{2}$ emission & $\mathrm{kg} / \mathrm{GJ}$ & E6 & $\min$ & [31-33] \\
\hline \multirow{7}{*}{ Financial } & Nominal equipment investment & $\mathrm{k} €$ & $\mathrm{~F} 1$ & $\min$ & [29] \\
\hline & Nominal install investment & $\mathrm{k} €$ & $\mathrm{~F} 2$ & $\min$ & [29] \\
\hline & Nominal additional investment & $\mathrm{k} €$ & F3 & $\min$ & [29] \\
\hline & Fixed electricity cost & $€ / y$ & $\mathrm{~F} 4$ & $\min$ & [29] \\
\hline & Fixed operating and maintenance cost & $€ / y$ & F5 & $\min$ & [29] \\
\hline & Fuel cost & $€ / \mathrm{GJ}$ & F6 & $\min$ & {$[31,34]$} \\
\hline & Subsidy & $\mathrm{k} €$ & F7 & $\max$ & [35] \\
\hline
\end{tabular}

\subsection{Empirical Data}

The represented data for individual heating systems are considered and calculated based on a typical single-family house with average characteristics, including $150 \mathrm{~m}^{2}$ area, $18 \mathrm{MWh}$ annual heat demand, $8 \mathrm{~kW}$ peak demand, $4 \mathrm{~kW}$ hot water capacity and average improvements for buildings built before 1979 [29]. This assumption also corresponds to the Evida report [13], where over $75 \%$ of participants in Denmark reside in a residential area between 100 and $200 \mathrm{~m}^{2}$.

The data are mainly collected from the Danish Energy Agency and its subsidiary. The measurement unit is unified through a calculation based on $1 \mathrm{MWh}=1000 \mathrm{kWh}=3.6 \mathrm{GJ}$ 
and EUR $1=$ DKK 7.45. The emission of district heating and heat pumps is calculated based on the used fuel distribution in district heating and electricity production and losses in the transition. The noise is set by the influence level and average $\mathrm{dB}$ of the available product. According to the Danish Executive Order, the fuel cost is a national average, and the subsidy is for specific heat pumps. Alternatives and the criteria matrix with all quantitative results are provided in Table 5.

Table 5. Alternatives and criteria matrix.

\begin{tabular}{|c|c|c|c|c|c|c|c|c|c|c|c|c|c|}
\hline Criteria & H1 & $\mathrm{H} 2$ & H3 & H4 & H5 & H6 & H7 & H8 & H9 & H10 & H11 & H12 & H13 \\
\hline $\mathrm{T} 1$ & 1.0 & 1.0 & 1.0 & 1.0 & 1.0 & 1.0 & 1.0 & 1.0 & 1.0 & 1.0 & 0.3 & 0.3 & 0.1 \\
\hline $\mathrm{T} 2$ & 1.0 & 1.0 & 1.0 & 1.0 & 1.0 & 1.0 & 1.0 & 1.0 & 1.0 & 1.0 & 0.0 & 0.0 & 0.7 \\
\hline $\mathrm{T} 3$ & 0.9 & 1.0 & 0.8 & 0.8 & 1.0 & 1.0 & 3.2 & 3.0 & 3.5 & 2.2 & 4.9 & 0.7 & 0.2 \\
\hline $\mathrm{T} 4$ & 20.0 & 20.0 & 20.0 & 20.0 & 25.0 & 25.0 & 16.0 & 12.0 & 20.0 & 18.0 & 12.0 & 20.0 & 25.0 \\
\hline $\mathrm{T} 5$ & 0.0 & 0.0 & 20.0 & 60.0 & 0.0 & 0.0 & 0.0 & 0.0 & 0.0 & 0.0 & 0.0 & 50.0 & 0.0 \\
\hline $\mathrm{T} 6$ & 42.0 & 42.0 & 42.0 & 42.0 & 25.0 & 25.0 & 52.0 & 67.0 & 42.0 & 50.0 & 64.0 & 49.0 & 25.0 \\
\hline E1 & 6.7 & 0.4 & 25.0 & 25.0 & 0.7 & 0.7 & 9.3 & 9.8 & 8.5 & 11.0 & 6.1 & 25.0 & 0.0 \\
\hline E2 & 5.0 & 0.1 & 14.0 & 14.0 & 0.1 & 0.1 & 0.3 & 0.3 & 0.2 & 0.3 & 0.2 & 28.8 & 0.0 \\
\hline E3 & 52.0 & 20.4 & 70.0 & 70.0 & 4.7 & 4.7 & 18.9 & 19.8 & 17.2 & 24.0 & 12.3 & 90.0 & 0.0 \\
\hline $\mathrm{E} 4$ & 0.0 & 1.0 & 2.0 & 2.0 & 0.2 & 0.2 & 0.1 & 0.1 & 0.1 & 0.2 & 0.1 & 125.0 & 0.0 \\
\hline E5 & 0.0 & 1.0 & 4.0 & 4.0 & 0.5 & 0.5 & 6.3 & 6.7 & 5.8 & 7.5 & 4.1 & 4.0 & 0.0 \\
\hline E6 & 74.1 & 49.5 & 0.0 & 0.0 & 2.6 & 2.6 & 11.5 & 12.0 & 10.5 & 13.4 & 7.4 & 0.0 & 0.0 \\
\hline $\mathrm{F} 1$ & 4.3 & 2.7 & 3.8 & 4.5 & 1.3 & 1.0 & 6.9 & 4.6 & 7.1 & 6.7 & 1.2 & 2.1 & 2.9 \\
\hline $\mathrm{F} 2$ & 1.3 & 1.2 & 1.1 & 1.9 & 1.1 & 1.1 & 4.0 & 4.0 & 7.5 & 4.6 & 0.5 & 0.4 & 1.2 \\
\hline F3 & 0.0 & 2.0 & 6.0 & 0.0 & 3.0 & 3.0 & 0.0 & 0.0 & 0.0 & 2.0 & 0.0 & 1.6 & 0.0 \\
\hline $\mathrm{F} 4$ & 9.7 & 9.7 & 16.6 & 13.8 & 8.3 & 2.8 & 0.0 & 0.0 & 0.0 & 0.0 & 0.0 & 0.0 & 3.5 \\
\hline F5 & 174.9 & 181.9 & 357.6 & 420.3 & 37.8 & 46.0 & 311.4 & 359.7 & 287.3 & 375.8 & 150.3 & 145.0 & 49.0 \\
\hline F6 & 14.0 & 10.4 & 14.2 & 14.2 & 26.1 & 26.1 & 26.0 & 26.0 & 26.0 & 26.0 & 26.0 & 7.5 & 0.0 \\
\hline F7 & 0.0 & 0.0 & 0.0 & 0.0 & 0.0 & 0.0 & 3.5 & 2.8 & 4.3 & 0.0 & 0.0 & 0.0 & 0.0 \\
\hline
\end{tabular}

\subsection{Weighting and Normalization Matrices}

Table 6 lists five weighting results from different weighting methods. Data highlighted with darker background colour means higher weight. Most weights have a good balance between different criteria with low deviation. However, a large variance can be noticed in the Std weighting method, highlighting criterion F5, fixed operating and maintenance cost with $44.4 \%$ weight. It will be evaluated by sensitive analysis. The results from four normalization methods are shown in Tables A1-A4 of Appendix A.

\subsection{MCDM Ranking Results and Analysis}

The 48 MCDM rankings resulted from the combination of 6 weighting methods, 2 evaluation methods, and 4 normalization methods are listed in Table A5 of Appendix A. The ranking results of TOPSIS have shown a larger variance, compared to VIKOR. As shown in Figure 3, the normalization methods heavily influence the ranking results in the same weighting method. However, a similar trend can be noticed in the same normalization methods, using different weighting. The ranking generated by VIKOR apparently will not change through different normalization methods and shares similarities when using different weighting methods, as shown in Figure 4. 
Table 6. Weights results of 19 criteria from 5 different weighting methods.

\begin{tabular}{ccccccc}
\hline Criteria & Mean & Std & Entropy & CRITIC & Angle & Gini \\
\hline T1 & 0.0526 & 0.0011 & 0.0033 & 0.0542 & 0.0279 & 0.0188 \\
T2 & 0.0526 & 0.0012 & 0.0804 & 0.0601 & 0.0307 & 0.0200 \\
T3 & 0.0526 & 0.0046 & 0.0086 & 0.0520 & 0.0483 & 0.0447 \\
T4 & 0.0526 & 0.0139 & 0.0007 & 0.0669 & 0.0154 & 0.0126 \\
T5 & 0.0526 & 0.0679 & 0.0804 & 0.0538 & 0.0818 & 0.0911 \\
T6 & 0.0526 & 0.0437 & 0.0014 & 0.0491 & 0.0212 & 0.0180 \\
E1 & 0.0526 & 0.0308 & 0.0804 & 0.0511 & 0.0550 & 0.0551 \\
E2 & 0.0526 & 0.0289 & 0.0804 & 0.0481 & 0.0776 & 0.0849 \\
E3 & 0.0526 & 0.0955 & 0.0804 & 0.0467 & 0.0544 & 0.0536 \\
E4 & 0.0526 & 0.1127 & 0.0804 & 0.0480 & 0.0943 & 0.1012 \\
E5 & 0.0526 & 0.0089 & 0.0804 & 0.0496 & 0.0483 & 0.0478 \\
E6 & 0.0526 & 0.0728 & 0.0804 & 0.0546 & 0.0730 & 0.0755 \\
F1 & 0.0526 & 0.0070 & 0.0049 & 0.0493 & 0.0370 & 0.0345 \\
F2 & 0.0526 & 0.0068 & 0.0103 & 0.0438 & 0.0530 & 0.0488 \\
F3 & 0.0526 & 0.0060 & 0.0804 & 0.0533 & 0.0678 & 0.0728 \\
F4 & 0.0526 & 0.0194 & 0.0804 & 0.0610 & 0.0633 & 0.0685 \\
F5 & 0.0526 & 0.4441 & 0.0061 & 0.0451 & 0.0392 & 0.0371 \\
F6 & 0.0526 & 0.0295 & 0.0804 & 0.0568 & 0.0322 & 0.0271 \\
F7 & 0.0526 & 0.0052 & 0.0804 & 0.0566 & 0.0796 & 0.0882 \\
\hline
\end{tabular}

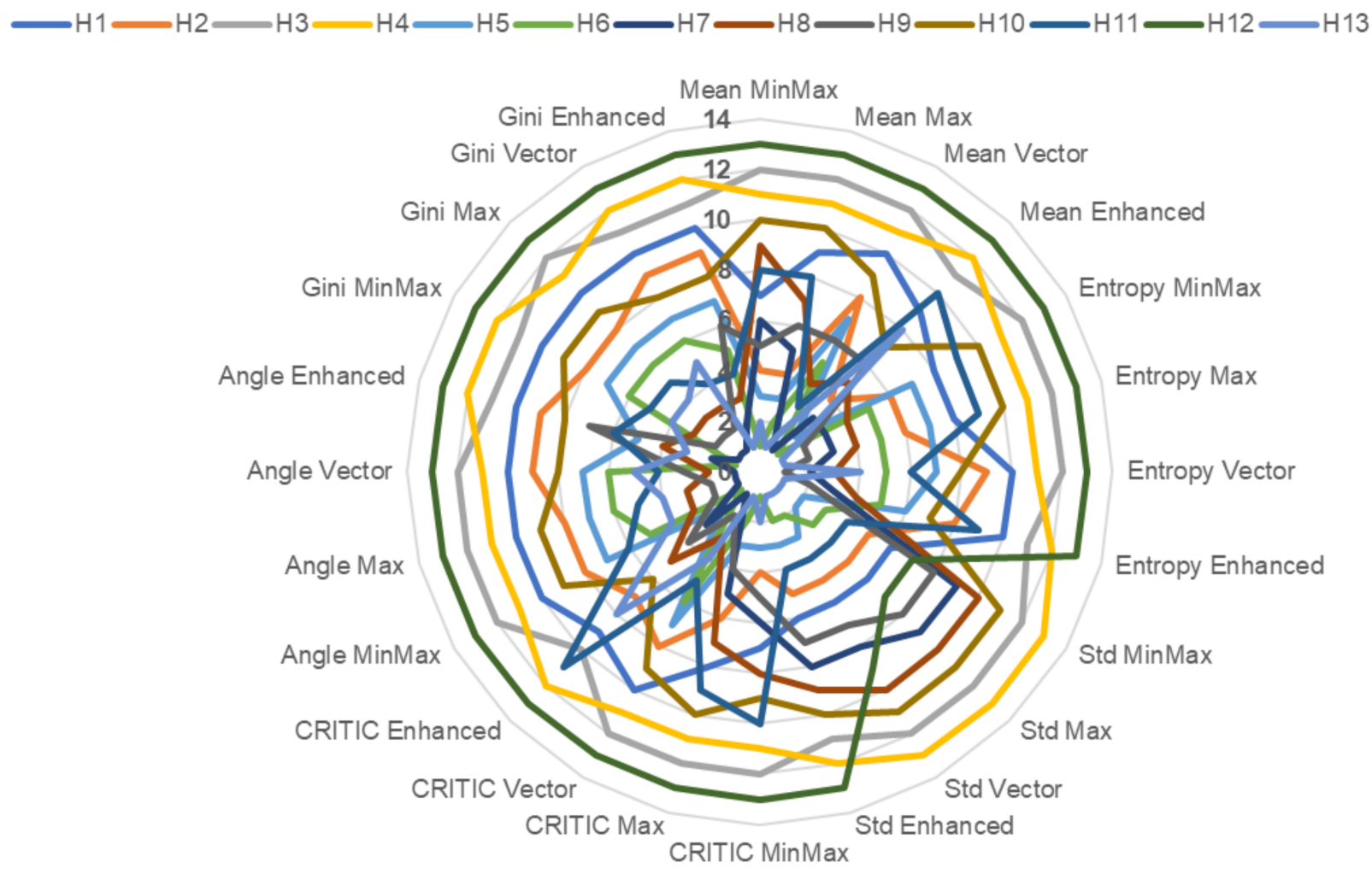

Figure 3. Ranking changes comparison in TOPSIS. 


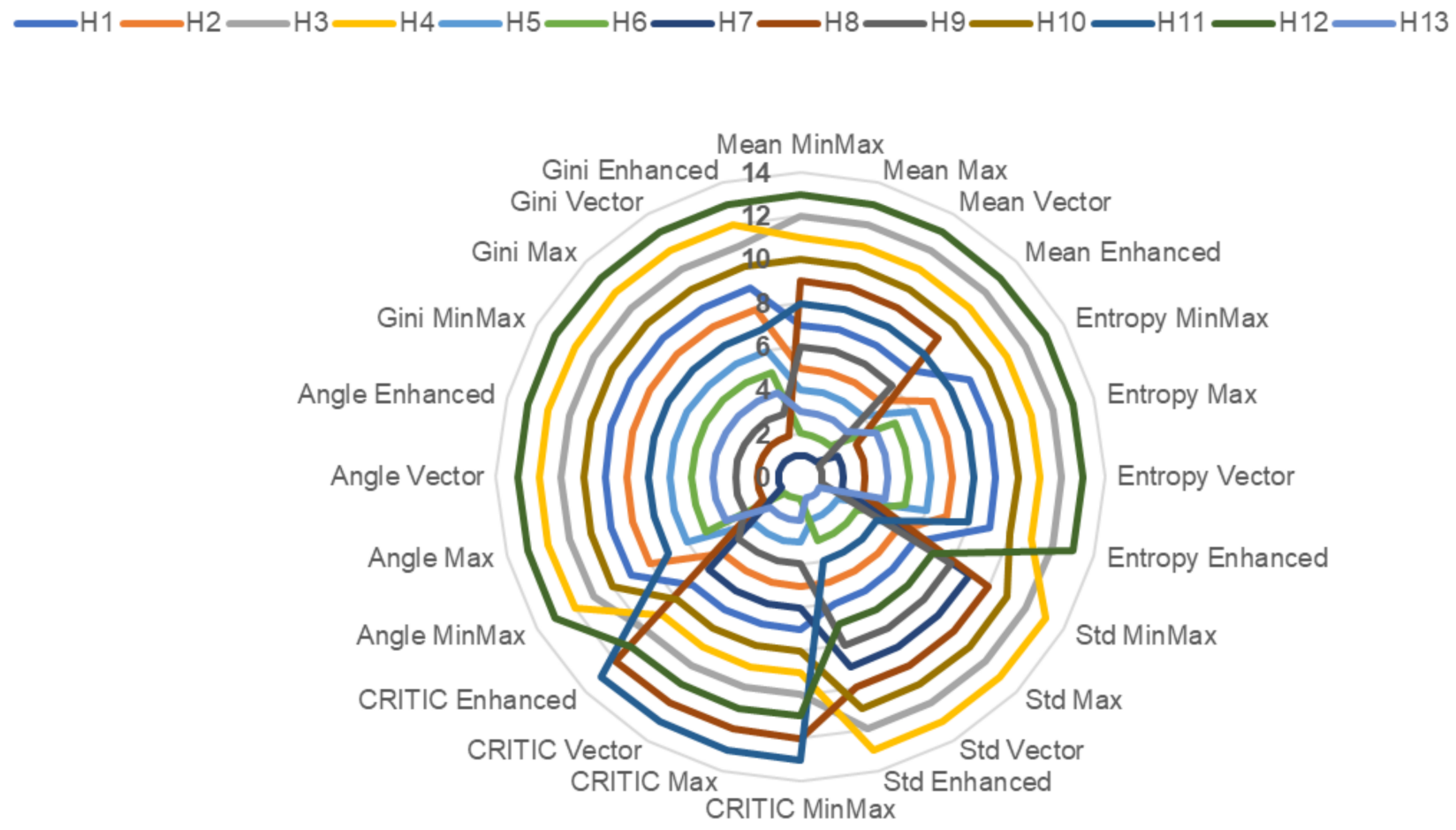

Figure 4. Ranking changes comparison in VIKOR.

Sensitive Analysis to $v$ in VIKOR

As the final score calculation formula of VIKOR is shown in Equation (4), there is a parameter $v$ to weight the strategy of maximum group utility, which represents the majority of the criteria [27]. Normally, $v$ is set to 0.5 to represent the risk-neutral group, which weighs the group utility and the individual regret equally. Hence, to generalize this decision making, the value of $v$ is changed to discover the influence of different preferences existing in a large number of national and even international decision makers.

The sensitive analysis results are listed in Table 7. The change of background colour in each column means ranking changes for this alternative under different sensitive scenarios at the following results tables. The rankings of $\mathrm{H} 3$ to $\mathrm{H} 9$ are more easily influenced by the change in $v$, where the ranking fluctuates in a certain range. However, the range of absolute value change is still logically reasonable on a large scale.

\subsection{Ensemble Results}

With the proposed fuzzy Cauchy distribution membership function, the ensemble ranking, shown in the first row of Table 8 , is as follows: (1) heat pump (air to water), (2) solar heating, (3) district heating (direct), (4) heat pump (ground source), (5) heat pump (air to water, low-price product), (6) district heating (indirect), (7) heat pump (air-to-air), (8) gas boiler, (9) oil boiler, (10) heat pump (gas-hybrid), (11) biomass boiler (manual), (12) biomass boiler (auto), and (13) woodstove. In order to validate the robustness of the ranking result, sensitive analysis of the possible influencing factors, which are the high variance weight and fuzzy parameter setting, is needed.

\subsubsection{Sensitive Analysis with or without High Variance Weight}

Since the Std weighting method generated a high variance weight range from 0.001 to 0.444 , a comparison experiment with and without Std weighting is conducted to evaluate how a high variance weight can influence the final ranking result. As shown in Table 8, six alternatives change one place, $\mathrm{H} 11$ and $\mathrm{H} 12$ exchange their rankings by changing two places, and the rest stay the same. Therefore, the proposed method can handle high weight variance. 
Table 7. Sensitive analysis results of changing parameter $v$ in VIKOR.

\begin{tabular}{ccccccccccccccc}
\hline $\boldsymbol{v}$ & H1 & H2 & H3 & H4 & H5 & H6 & H7 & H8 & H9 & H10 & H11 & H12 & H13 \\
\hline 0.05 & 9 & 7 & 12 & 13 & 6 & 5 & 1 & 4 & 3 & 10 & 8 & 11 & 2 \\
0.1 & 9 & 7 & 13 & 12 & 6 & 4 & 1 & 5 & 3 & 10 & 8 & 11 & 2 \\
0.15 & 9 & 7 & 13 & 12 & 6 & 4 & 1 & 5 & 3 & 10 & 8 & 11 & 2 \\
0.2 & 9 & 7 & 13 & 12 & 6 & 4 & 1 & 5 & 3 & 10 & 8 & 11 & 2 \\
0.25 & 9 & 7 & 13 & 12 & 6 & 4 & 1 & 5 & 3 & 10 & 8 & 11 & 2 \\
0.3 & 9 & 7 & 13 & 12 & 6 & 4 & 1 & 5 & 3 & 10 & 8 & 11 & 2 \\
0.35 & 9 & 7 & 11 & 12 & 6 & 4 & 1 & 5 & 3 & 10 & 8 & 13 & 2 \\
0.4 & 9 & 7 & 12 & 11 & 6 & 4 & 1 & 5 & 3 & 10 & 8 & 13 & 2 \\
0.45 & 9 & 7 & 12 & 11 & 6 & 3 & 1 & 5 & 4 & 10 & 8 & 13 & 2 \\
0.5 & 9 & 7 & 12 & 11 & 6 & 3 & 1 & 5 & 4 & 10 & 8 & 13 & 2 \\
0.55 & 9 & 7 & 12 & 11 & 6 & 3 & 1 & 5 & 4 & 10 & 8 & 13 & 2 \\
0.6 & 9 & 7 & 12 & 11 & 5 & 3 & 1 & 6 & 4 & 10 & 8 & 13 & 2 \\
0.65 & 9 & 7 & 12 & 11 & 5 & 3 & 1 & 6 & 4 & 10 & 8 & 13 & 2 \\
0.7 & 9 & 7 & 12 & 11 & 5 & 3 & 1 & 6 & 4 & 10 & 8 & 13 & 2 \\
0.75 & 9 & 7 & 13 & 11 & 5 & 3 & 1 & 6 & 4 & 10 & 8 & 12 & 2 \\
0.8 & 9 & 7 & 13 & 11 & 5 & 3 & 2 & 6 & 4 & 10 & 8 & 12 & 1 \\
0.85 & 9 & 6 & 12 & 11 & 5 & 2 & 4 & 7 & 3 & 10 & 8 & 13 & 1 \\
0.9 & 9 & 6 & 12 & 11 & 4 & 2 & 5 & 7 & 3 & 10 & 8 & 13 & 1 \\
0.95 & 9 & 6 & 12 & 11 & 3 & 2 & 5 & 8 & 4 & 10 & 7 & 13 & 1 \\
1 & 9 & 5 & 12 & 11 & 3 & 2 & 6 & 8 & 4 & 10 & 7 & 13 & 1 \\
\hline
\end{tabular}

Table 8. Final ensemble ranking with or without the ranking results calculated by Std weighting.

\begin{tabular}{cccccccccccccc}
\hline & H1 & H2 & H3 & H4 & H5 & H6 & H7 & H8 & H9 & H10 & H11 & H12 & H13 \\
\hline $\begin{array}{c}\text { With } \\
\text { std }\end{array}$ & 9 & 8 & 12 & 11 & 6 & 3 & 1 & 5 & 4 & 10 & 7 & 13 & 2 \\
$\begin{array}{c}\text { Without } \\
\text { std }\end{array}$ & 9 & 7 & 12 & 11 & 6 & 4 & 1 & 5 & 3 & 10 & 8 & 13 & 2 \\
\hline
\end{tabular}

\subsubsection{Sensitive Analysis to the Fuzzy Ensemble Method}

The parameter of the original fuzzy Cauchy distribution membership function is set based on the theory that decision makers prefer top-ranking alternatives more. However, the preference degree could change in a certain range, so the influence of different membership values is tested below.

When ranking $=1$, membership $=y_{1}, \mathrm{a}=\frac{25 y_{1}}{\left(1-y_{1}\right)\left(1-\sqrt{\frac{9 y_{1}}{1-y_{1}}}\right)^{2}}, \mathrm{~b}=\frac{6-\sqrt{\frac{9 y_{1}}{1-y_{1}}}}{1-\sqrt{\frac{9 y_{1}}{1-y_{1}}}}, \mathrm{c}=\frac{1}{10 \ln \frac{13}{6}}$, and $\mathrm{d}=\frac{\ln 13}{10 \ln \frac{13}{6}}-1$, then the following $f(x)$ can be calculated by Equation (5) when $y_{1}$ varies from 0.6 to 0.999 as shown in Figure 5.

When ranking $=6$, membership $=y_{2}, \mathrm{a}=\frac{25 y_{2}}{\left(1-y_{2}\right)\left(1-\sqrt{\frac{y_{2}}{9\left(1-y_{2}\right)}}\right)^{2}}, \mathrm{~b}=6-\frac{5}{1-\sqrt{\frac{y_{2}}{9\left(1-y_{2}\right)}}}$, and $\mathrm{c}=\frac{y_{2}}{\ln \frac{13}{6}}, \mathrm{~d}=\frac{y_{2} \ln 13}{\ln \frac{13}{6}}-1$, then the following $f(x)$ can be calculated by Equation (5) when $y_{2}$ varies from 0.01 to 0.19 as shown in Figure 6.

When ranking $=13$, membership $=y_{3}, a=\frac{225}{64}, b=\frac{3}{8}, c=\frac{0.1-y_{3}}{\ln \frac{13}{6}}$, and $d=\frac{\left(0.1-y_{3}\right) \ln 6}{\ln \frac{13}{6}}-0.9$, then the following $f(x)$ can be calculated by Equation (1) when $y_{3}$ vary from 0 to 0.1 as shown in Figure 7. The final ensemble ranking results in Table 9 show a rather consistent ranking while facing different membership. It shows that the ranking starts to change when y 1 takes values of 0.8 and above and when y2 takes values of 0.13 and above. The membership of $\mathrm{y} 3$ is relatively stable since the ranking changes only when it takes 0.1 . 


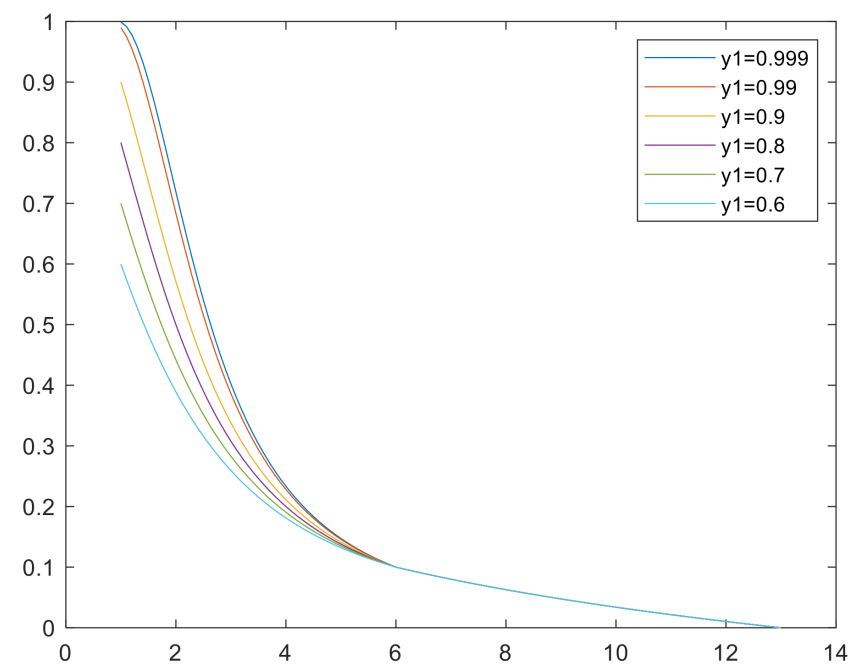

Figure 5. The $f(x)$ changes trend in different membership y1.

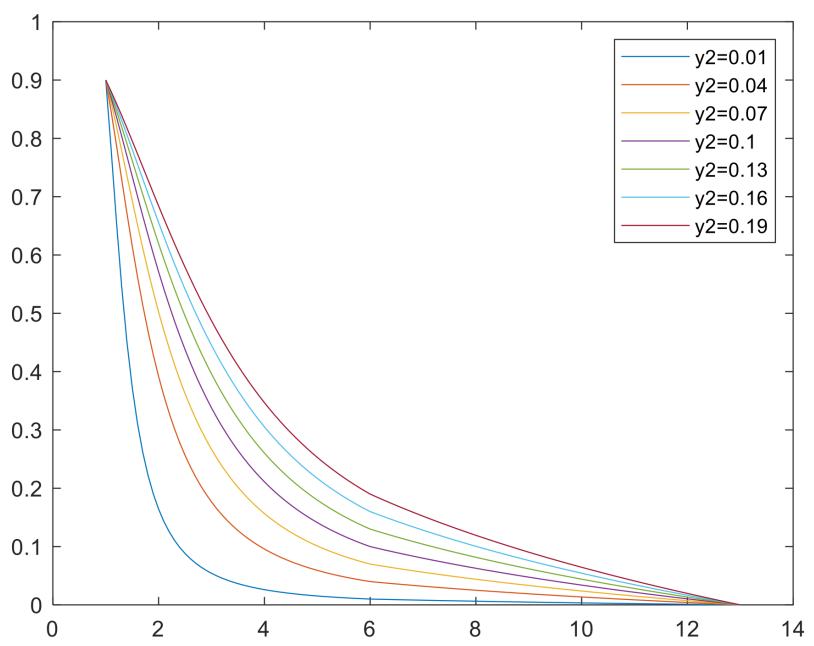

Figure 6. The $f(x)$ changes trend in different membership y2.

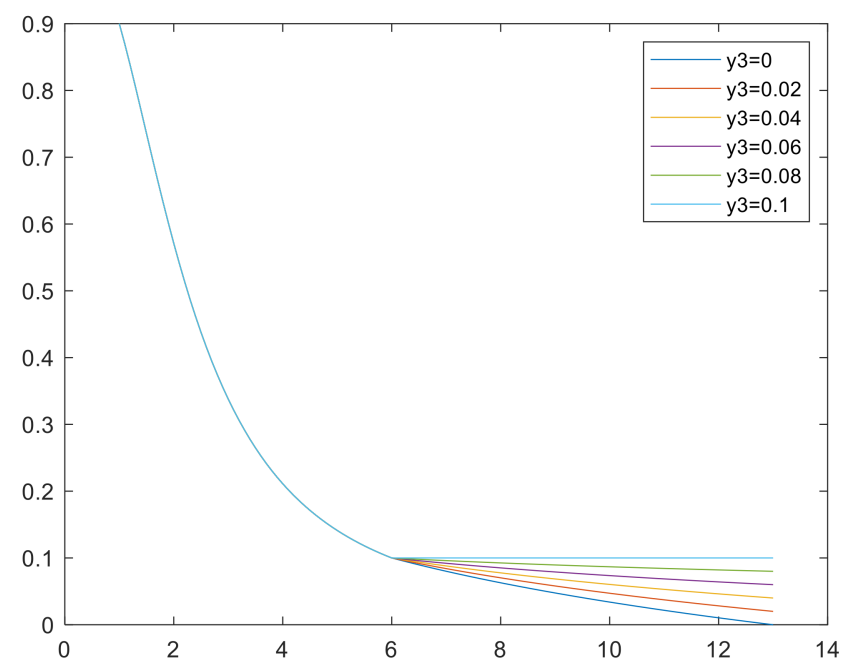

Figure 7. The $f(x)$ changes trend in different membership y3. 
Table 9. Fuzzy ensemble rankings under different membership.

\begin{tabular}{ccccccccccccccc}
\hline Variables & Value & H1 & H2 & H3 & H4 & H5 & H6 & H7 & H8 & H9 & H10 & H11 & H12 & H13 \\
\hline & 0.6 & 9 & 7 & 12 & 11 & 5 & 3 & 1 & 6 & 4 & 10 & 8 & 13 & 2 \\
& 0.7 & 9 & 7 & 12 & 11 & 5 & 3 & 1 & 6 & 4 & 10 & 8 & 13 & 2 \\
Fuzzy_y1 & 0.8 & 9 & 8 & 12 & 11 & 5 & 3 & 1 & 6 & 4 & 10 & 7 & 13 & 2 \\
& 0.9 & 9 & 8 & 12 & 11 & 6 & 3 & 1 & 5 & 4 & 10 & 7 & 13 & 2 \\
& 0.99 & 9 & 8 & 12 & 11 & 6 & 3 & 1 & 5 & 4 & 10 & 7 & 13 & 2 \\
& 0.999 & 9 & 8 & 12 & 11 & 6 & 3 & 1 & 5 & 4 & 10 & 7 & 13 & 2 \\
\hline & 0.01 & 9 & 8 & 12 & 11 & 6 & 3 & 1 & 5 & 4 & 10 & 7 & 13 & 2 \\
& 0.04 & 9 & 8 & 12 & 11 & 6 & 3 & 1 & 5 & 4 & 10 & 7 & 13 & 2 \\
& 0.07 & 9 & 8 & 12 & 11 & 6 & 3 & 1 & 5 & 4 & 10 & 7 & 13 & 2 \\
Fuzzy_y2 & 0.1 & 9 & 8 & 12 & 11 & 6 & 3 & 1 & 5 & 4 & 10 & 7 & 13 & 2 \\
& 0.13 & 9 & 8 & 12 & 11 & 5 & 3 & 1 & 6 & 4 & 10 & 7 & 13 & 2 \\
& 0.16 & 9 & 7 & 12 & 11 & 5 & 3 & 1 & 6 & 4 & 10 & 8 & 13 & 2 \\
& 0.19 & 9 & 7 & 12 & 11 & 5 & 3 & 1 & 6 & 4 & 10 & 8 & 13 & 2 \\
\hline & 0 & 9 & 8 & 12 & 11 & 6 & 3 & 1 & 5 & 4 & 10 & 7 & 13 & 2 \\
& 0.02 & 9 & 8 & 12 & 11 & 6 & 3 & 1 & 5 & 4 & 10 & 7 & 13 & 2 \\
& 0.04 & 9 & 8 & 12 & 11 & 6 & 3 & 1 & 5 & 4 & 10 & 7 & 13 & 2 \\
& 0.06 & 9 & 8 & 12 & 11 & 6 & 3 & 1 & 5 & 4 & 10 & 7 & 13 & 2 \\
& 0.08 & 9 & 8 & 12 & 11 & 6 & 3 & 1 & 5 & 4 & 10 & 7 & 13 & 2 \\
& 0.1 & 13 & 8 & 12 & 11 & 6 & 3 & 1 & 5 & 4 & 10 & 7 & 9 & 2 \\
\hline
\end{tabular}

\section{Discussion}

Based on previous analysis and comparison between VIKOR and TOPSIS methods $[27,36]$, this paper introduced a framework that combines both methods with multiple weighting and normalization methods to generate comprehensive rankings for heat alternatives decision support, followed by ensemble learning with fuzzy membership function to generate a final ranking. Although the fuzzy theory is widely used with MCDM [37], it is mainly used during the weighting and evaluating methods inside MCDM to handle the fuzzy environment and subjective information. In this paper, the fuzzy membership function was applied after the MCDM ranking. Additionally, the ensemble learning methodology is widely used in machine learning, but it is rarely found in MCDM. The proposed framework achieves an optimal combination for decision support of heating alternatives. The ensemble learning with fuzzy membership function has shown great robustness by effectively reducing the outcome variance while altering the value of each criterion. Thus, customized changes in each criterion can provide a relatively stable and accurate ranking for heat alternatives decision support.

\subsection{Comparative Analysis}

This framework has provided a full, detailed, yet generalized ranking of heating alternatives. It contains 13 heating alternatives that are available in product markets. Compared to the previous study [38], the comparison is based on more detailed alternatives within the same kind of technology. For example, the biomass boiler is divided into auto and manual categories. The variety ranking of different heat pumps in the final result also proves the necessity of separating heating alternatives for individual households while facing these detailed comparisons in real life. In addition, the inclusion of all alternatives allows individuals to compare the currently installed heat technology with possible heat alternatives, providing a clear vision of improvements or gaps.

In the meantime, while expanding the comparison list, the ranking result is relatively consistent with previous research on Denmark, using single TOPSIS, which concludes that solar heating is better than heat pumps as a whole and better than wood pellet (biomass) boilers [38]. In the ranking calculated in this paper, solar heating does not rank in the first position. The main influencing factors in the ranking of solar heating are its limitations in annual energy transfer efficiency and new subsidy policy toward heat pumps [38]. Solar heating and the other two types-air-to-air heat pumps and woodstoves-are only used as supplemental heating alternatives, but their reasons are different. Woodstoves and 
air-to-air heat pumps are limited by their designs, which can only heat specific regions regarding the entire living space. Solar heating is limited by its efficiency and storage needs, considering that it heavily depends on the sunlight period length and the mismatch between solar energy supply and heat demand. Thus, with more development in solarrelated technologies, the potential of solar heating is still significant.

The air-to-water heat pump, which ranks before solar heating, has a subsidy from the Danish government for green heat transition, while solar heating does not. To measure the influence of the subsidy, a scenario of a no-subsidy case is studied and examined by the same process without the subsidy (F7). In this test, the three heat pumps with the subsidy fall to rank as six to eight with the same relative order, where air-to-water $>$ ground-source $>$ low-price air-to-water heat pumps; the new top five are solar heating, direct district heating, air-to-air heat pump, gas boiler and indirect district heating.

\subsection{Managerial Implications}

The comparative analysis of the ranking without the subsidy shows a significant influence of the subsidy toward ranking and provides insights to municipalities on how the subsidy might influence households' preferences based on the framework proposed in this paper. This also acts as an example to those organizations considering promoting certain technologies by subsidy.

In the context of heating transition decisions, the generated ranking could act as a theoretical guideline for both municipalities and households. For municipalities, the heat/energy planners can use this tool to develop heating plans and communicate to building owners who need to make heating decisions. It can also be a tool for municipalities to educate households to change to certain suitable solutions based on the quantified method with objective ranking results, which is much more persuasive. For households, Figure 8 shows an example of how this generalized framework derived from the proposed method can apply in real life. According to the climate coordinator and energy planner in the partner municipality in Denmark, households often need advice in changing their heating system. Usually, households turn to local installers for opinions, but they might be subjective and influenced by what they sell and are used to installing. Hence, the ranking contains all available heating alternatives in the market and can act as a comprehensive guideline to prevent potentially biased opinions. With this information, the decision makers can easily choose optimal heating alternatives from the practical, feasible heating sets influenced by personal and realistic factors. Apart from the final rankings, decision makers can overview the intuitive quantified indicators of the summarized alternatives and criteria matrix to match their personal preferences.

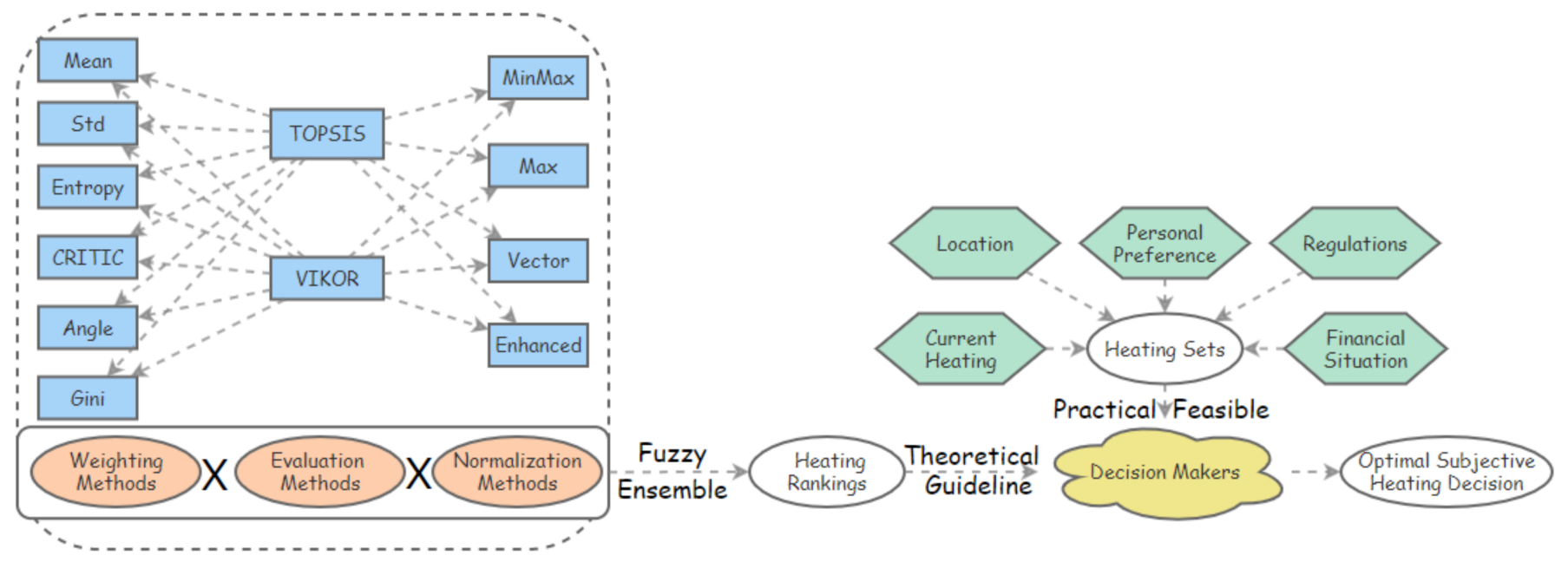

Figure 8. Generalized application framework. 
Real cases face the problems discussed above in Lyngby-Tårbæks, Denmark. The households located in areas without district heating use gas or oil boilers for year-round heating. Hence, there are around 8000 natural gas boilers and 800 oil boilers in year-round homes that must be fossil-free by 2035 in the energy transition plan of Lyngby-Tårbæks. If the households want to replace the old boilers, the air-to-water heat pump would be the first suggestion. If the households do not want to invest too much initially, they could obtain a heat pump by subscription, which will be owned and maintained by companies. However, if they are sensitive to noise, they could consider a ground-source heat pump. If the households are only looking for supplementary heating, solar heating could be their first choice.

\section{Conclusions}

Nowadays, the energy transition toward carbon neutrality has become a growing consensus among worldwide countries, and heating is a huge part of it. While facing the challenge of self-salvation through carbon neutrality, this research contributes to helping the heating energy transition in Denmark and globally. Denmark is one of the pioneer cases within the EU. Many municipalities need this kind of decision support instrument to better communicate with residents to achieve a smooth energy transition. Considering multiple criteria regarding different households living in buildings with different current heating systems and various physical factors, choosing a suitable solution from numerous options for a specific household and a certain building becomes difficult. The goals of residences, municipalities and researchers are the same regarding minimizing costs and carbon emissions.

Hence, the contribution of this paper is to provide a framework to support the decision making process with multiple alternatives and criteria to be considered. With the data from Denmark, the methodology used in this paper is mainly based on VIKOR and TOPSIS within MCDM. An ensemble learning method is applied to finalize the ultimate ranking. The framework and methodology proposed in this paper could be easily and broadly applied to other regions and fields to support the decision making process.

Another contribution is a comprehensive comparison of 13 individual heating alternatives available in Denmark through the proposed framework and the data from the Danish Energy Agency. The comprehensive comparison could provide a full picture for both Danish households and municipalities of each Danish region regarding the currently and potentially available heating technologies' advantages and disadvantages under the same standard. The ranking results produced by the proposed framework provide a quantified and objective perspective. For the households who face the situation of selecting a heating technology, the suggestions provided by the energy suppliers usually include their preference, which policies or their profits might influence. Thus, a full and objective comparison may protect the decision makers from the influences of other parties. Later, with a full understanding of each solution, decision makers' choices with their preferences can be made.

There are limitations of the proposed framework, and some possible future work can be done. Considering the potential differences in policy, economic status, and usability in each Danish region, it must be understood that in order to generalize the scope of the ranking, the data used in the case of this paper are based on the Danish national average. It might not be fully applicable to each specific situation. However, the methodology and framework proposed in this research can be easily adopted with new data regarding certain situations of each region, and more specific ranking results can be presented. The influence of the result on decision makers has not yet been researched. Hence, further work will focus on the interaction with decision makers and consider the whole framework in Figure 8 in the modeling to generate tailored, optimal alternatives for one's specific needs. Based on this research, an intelligent decision support tool could be developed and opened to the public with a user-friendly interface. Rather than using it as a guidebook to compare currently installed technologies with possible heating alternatives, individuals 
could alter the value of each criterion based on their own situation so that the result would be further customized.

In order to stabilize the ultimate ranking of each alternative, a large number of primary ranking sets are generated by going through different normalization, weighting, and MCDM methods. This paper applies only two classic, ideal-based MCDM methods, TOPSIS and VIKOR, as the basic MCDM solution generators. However, there are many variations, and other MCDM methods could be further involved to generate an even larger number of primary ranking sets, which can be used to strengthen the stability of the final ranking through ensemble learning methods.

Author Contributions: Conceptualization, Q.W. and Y.L.; methodology, Q.W. and Q.Y.; software, Q.W.; validation, Q.W. and Q.Y.; formal analysis, Q.W. and J.Q.; investigation, Q.W.; resources, Q.W.; data curation, Q.W.; writing-original draft preparation, Q.W. and J.Q.; writing-review and editing, Y.L.; visualization, Q.W. and Q.Y.; supervision, Y.L.; project administration, Y.L.; funding acquisition, Y.L. All authors have read and agreed to the published version of the manuscript.

Funding: This research was funded by FlexSUS: Flexibility for Smart Urban Energy Systems (Project No. 91352), which has received funding in the framework of the joint programming initiative ERA-Net Smart Energy Systems' focus initiative Integrated, Regional Energy Systems, with support from the European Union's Horizon 2020 research and innovation program under grant agreement No. 775970. The usual disclaimer applies. This research was also partially funded by the Alliance Joint Research and Publication Seed Funding.

Institutional Review Board Statement: Not applicable.

Informed Consent Statement: Not applicable.

Data Availability Statement: Data are contained within the article. The data presented in this study are available in this article.

Acknowledgments: The authors acknowledge Claire Bergaentzlé, Jakob Jespersen, Philipp Andreas Gunkel, Mohammad Ansarin, Hyunkyo Yu, Leise Jebahar, Xin Lin, Dongqi Wang, Dakang Huang for their valuable insights related to this work.

Conflicts of Interest: The authors declare no conflict of interest. The funders had no role in the design of the study; in the collection, analyses, or interpretation of data; in the writing of the manuscript, or in the decision to publish the results.

Appendix A

Table A1. MinMax normalized matrix.

\begin{tabular}{|c|c|c|c|c|c|c|c|c|c|c|c|c|c|}
\hline Minmax & H1 & $\mathrm{H} 2$ & H3 & H4 & H5 & H6 & H7 & H8 & H9 & H10 & H11 & H12 & H13 \\
\hline $\mathrm{T} 1$ & 0.0000 & 0.0000 & 0.0000 & 0.0000 & 0.0000 & 0.0000 & 0.0000 & 0.0000 & 0.0000 & 0.0000 & 0.7778 & 0.7778 & 1.0000 \\
\hline T2 & 0.0000 & 0.0000 & 0.0000 & 0.0000 & 0.0000 & 0.0000 & 0.0000 & 0.0000 & 0.0000 & 0.0000 & 1.0000 & 1.0000 & 0.3000 \\
\hline T3 & 0.8511 & 0.8298 & 0.8723 & 0.8723 & 0.8298 & 0.8298 & 0.3617 & 0.4043 & 0.2979 & 0.5745 & 0.0000 & 0.8936 & 1.0000 \\
\hline $\mathrm{T} 4$ & 0.3846 & 0.3846 & 0.3846 & 0.3846 & 0.0000 & 0.0000 & 0.6923 & 1.0000 & 0.3846 & 0.5385 & 1.0000 & 0.3846 & 0.0000 \\
\hline T5 & 0.0000 & 0.0000 & 0.3333 & 1.0000 & 0.0000 & 0.0000 & 0.0000 & 0.0000 & 0.0000 & 0.0000 & 0.0000 & 0.8333 & 0.0000 \\
\hline T6 & 0.4048 & 0.4048 & 0.4048 & 0.4048 & 0.0000 & 0.0000 & 0.6429 & 1.0000 & 0.4048 & 0.5952 & 0.9286 & 0.5714 & 0.0000 \\
\hline E1 & 0.2680 & 0.0160 & 1.0000 & 1.0000 & 0.0280 & 0.0280 & 0.3720 & 0.3920 & 0.3400 & 0.4400 & 0.2440 & 1.0000 & 0.0000 \\
\hline E2 & 0.1736 & 0.0035 & 0.4861 & 0.4861 & 0.0035 & 0.0035 & 0.0104 & 0.0104 & 0.0069 & 0.0104 & 0.0069 & 1.0000 & 0.0000 \\
\hline E3 & 0.5778 & 0.2267 & 0.7778 & 0.7778 & 0.0522 & 0.0522 & 0.2100 & 0.2200 & 0.1911 & 0.2667 & 0.1367 & 1.0000 & 0.0000 \\
\hline E4 & 0.0000 & 0.0080 & 0.0160 & 0.0160 & 0.0016 & 0.0016 & 0.0008 & 0.0008 & 0.0008 & 0.0016 & 0.0008 & 1.0000 & 0.0000 \\
\hline E5 & 0.0000 & 0.1333 & 0.5333 & 0.5333 & 0.0667 & 0.0667 & 0.8400 & 0.8933 & 0.7733 & 1.0000 & 0.5467 & 0.5333 & 0.0000 \\
\hline E6 & 1.0000 & 0.6680 & 0.0000 & 0.0000 & 0.0351 & 0.0351 & 0.1552 & 0.1619 & 0.1417 & 0.1808 & 0.0999 & 0.0000 & 0.0000 \\
\hline F1 & 0.5410 & 0.2787 & 0.4590 & 0.5738 & 0.0492 & 0.0000 & 0.9672 & 0.5902 & 1.0000 & 0.9344 & 0.0328 & 0.1803 & 0.3115 \\
\hline F2 & 0.1268 & 0.1127 & 0.0986 & 0.2113 & 0.0986 & 0.0986 & 0.5070 & 0.5070 & 1.0000 & 0.5915 & 0.0141 & 0.0000 & 0.1127 \\
\hline F3 & 0.0000 & 0.3333 & 1.0000 & 0.0000 & 0.5000 & 0.5000 & 0.0000 & 0.0000 & 0.0000 & 0.3333 & 0.0000 & 0.2667 & 0.0000 \\
\hline F4 & 0.5843 & 0.5843 & 1.0000 & 0.8313 & 0.5000 & 0.1687 & 0.0000 & 0.0000 & 0.0000 & 0.0000 & 0.0000 & 0.0000 & 0.2108 \\
\hline F5 & 0.3584 & 0.3767 & 0.8361 & 1.0000 & 0.0000 & 0.0214 & 0.7153 & 0.8416 & 0.6523 & 0.8837 & 0.2941 & 0.2803 & 0.0293 \\
\hline F6 & 0.5364 & 0.3985 & 0.5441 & 0.5441 & 1.0000 & 1.0000 & 0.9962 & 0.9962 & 0.9962 & 0.9962 & 0.9962 & 0.2874 & 0.0000 \\
\hline F7 & 1.0000 & 1.0000 & 1.0000 & 1.0000 & 1.0000 & 1.0000 & 0.1860 & 0.3488 & 0.0000 & 1.0000 & 1.0000 & 1.0000 & 1.0000 \\
\hline
\end{tabular}


Table A2. Max normalized matrix.

\begin{tabular}{|c|c|c|c|c|c|c|c|c|c|c|c|c|c|}
\hline Max & H1 & $\mathrm{H} 2$ & H3 & H4 & H5 & H6 & H7 & H8 & H9 & H10 & H11 & H12 & H13 \\
\hline $\mathrm{T} 1$ & 0.0000 & 0.0000 & 0.0000 & 0.0000 & 0.0000 & 0.0000 & 0.0000 & 0.0000 & 0.0000 & 0.0000 & 0.7000 & 0.7000 & 0.9000 \\
\hline $\mathrm{T} 2$ & 0.0000 & 0.0000 & 0.0000 & 0.0000 & 0.0000 & 0.0000 & 0.0000 & 0.0000 & 0.0000 & 0.0000 & 1.0000 & 1.0000 & 0.3000 \\
\hline T3 & 0.8163 & 0.7959 & 0.8367 & 0.8367 & 0.7959 & 0.7959 & 0.3469 & 0.3878 & 0.2857 & 0.5510 & 0.0000 & 0.8571 & 0.9592 \\
\hline $\mathrm{T} 4$ & 0.2000 & 0.2000 & 0.2000 & 0.2000 & 0.0000 & 0.0000 & 0.3600 & 0.5200 & 0.2000 & 0.2800 & 0.5200 & 0.2000 & 0.0000 \\
\hline T5 & 0.0000 & 0.0000 & 0.3333 & 1.0000 & 0.0000 & 0.0000 & 0.0000 & 0.0000 & 0.0000 & 0.0000 & 0.0000 & 0.8333 & 0.0000 \\
\hline T6 & 0.6269 & 0.6269 & 0.6269 & 0.6269 & 0.3731 & 0.3731 & 0.7761 & 1.0000 & 0.6269 & 0.7463 & 0.9552 & 0.7313 & 0.3731 \\
\hline E1 & 0.2680 & 0.0160 & 1.0000 & 1.0000 & 0.0280 & 0.0280 & 0.3720 & 0.3920 & 0.3400 & 0.4400 & 0.2440 & 1.0000 & 0.0000 \\
\hline E2 & 0.1736 & 0.0035 & 0.4861 & 0.4861 & 0.0035 & 0.0035 & 0.0104 & 0.0104 & 0.0069 & 0.0104 & 0.0069 & 1.0000 & 0.0000 \\
\hline E3 & 0.5778 & 0.2267 & 0.7778 & 0.7778 & 0.0522 & 0.0522 & 0.2100 & 0.2200 & 0.1911 & 0.2667 & 0.1367 & 1.0000 & 0.0000 \\
\hline E4 & 0.0000 & 0.0080 & 0.0160 & 0.0160 & 0.0016 & 0.0016 & 0.0008 & 0.0008 & 0.0008 & 0.0016 & 0.0008 & 1.0000 & 0.0000 \\
\hline E5 & 0.0000 & 0.1333 & 0.5333 & 0.5333 & 0.0667 & 0.0667 & 0.8400 & 0.8933 & 0.7733 & 1.0000 & 0.5467 & 0.5333 & 0.0000 \\
\hline E6 & 1.0000 & 0.6680 & 0.0000 & 0.0000 & 0.0351 & 0.0351 & 0.1552 & 0.1619 & 0.1417 & 0.1808 & 0.0999 & 0.0000 & 0.0000 \\
\hline $\mathrm{F} 1$ & 0.6056 & 0.3803 & 0.5352 & 0.6338 & 0.1831 & 0.1408 & 0.9718 & 0.6479 & 1.0000 & 0.9437 & 0.1690 & 0.2958 & 0.4085 \\
\hline F2 & 0.1733 & 0.1600 & 0.1467 & 0.2533 & 0.1467 & 0.1467 & 0.5333 & 0.5333 & 1.0000 & 0.6133 & 0.0667 & 0.0533 & 0.1600 \\
\hline F3 & 0.0000 & 0.3333 & 1.0000 & 0.0000 & 0.5000 & 0.5000 & 0.0000 & 0.0000 & 0.0000 & 0.3333 & 0.0000 & 0.2667 & 0.0000 \\
\hline $\mathrm{F} 4$ & 0.5843 & 0.5843 & 1.0000 & 0.8313 & 0.5000 & 0.1687 & 0.0000 & 0.0000 & 0.0000 & 0.0000 & 0.0000 & 0.0000 & 0.2108 \\
\hline F5 & 0.4161 & 0.4328 & 0.8508 & 1.0000 & 0.0899 & 0.1094 & 0.7409 & 0.8558 & 0.6836 & 0.8941 & 0.3576 & 0.3450 & 0.1166 \\
\hline F6 & 0.5364 & 0.3985 & 0.5441 & 0.5441 & 1.0000 & 1.0000 & 0.9962 & 0.9962 & 0.9962 & 0.9962 & 0.9962 & 0.2874 & 0.0000 \\
\hline F7 & 1.0000 & 1.0000 & 1.0000 & 1.0000 & 1.0000 & 1.0000 & 0.1860 & 0.3488 & 0.0000 & 1.0000 & 1.0000 & 1.0000 & 1.0000 \\
\hline
\end{tabular}

Table A3. Vector normalized matrix.

\begin{tabular}{|c|c|c|c|c|c|c|c|c|c|c|c|c|c|}
\hline Vector & H1 & H2 & H3 & H4 & H5 & H6 & H7 & H8 & H9 & H10 & H11 & H12 & H13 \\
\hline $\mathrm{T} 1$ & 0.6867 & 0.6867 & 0.6867 & 0.6867 & 0.6867 & 0.6867 & 0.6867 & 0.6867 & 0.6867 & 0.6867 & 0.9060 & 0.9060 & .9687 \\
\hline $\mathrm{T} 2$ & 0.6912 & 0.6912 & 0.6912 & 0.6912 & 0.6912 & 0.6912 & 0.6912 & 0.6912 & 0.6912 & 0.6912 & 1.0000 & .0000 & .7839 \\
\hline T3 & 0.8892 & 0.8769 & 0.9015 & 0.9015 & 0.8769 & 0.8769 & 0.6060 & 0.6306 & 0.5690 & 0.7291 & 0.3967 & 0.9138 & 0.9754 \\
\hline $\mathrm{T} 4$ & 0.7211 & 0.7211 & 0.7211 & 0.7211 & 0.6514 & 0.6514 & 0.7769 & 0.8327 & 0.7211 & 0.7490 & 0.8327 & 0.7211 & 0.6514 \\
\hline T5 & 0.0000 & 0.0000 & 0.2481 & 0.7442 & 0.0000 & 0.0000 & 0.0000 & 0.0000 & 0.0000 & 0.0000 & 0.0000 & 0.6202 & 0.0000 \\
\hline T6 & 0.2561 & 0.2561 & 0.2561 & 0.2561 & 0.1525 & 0.1525 & 0.3171 & 0.4086 & 0.2561 & 0.3049 & 0.3903 & 0.2988 & 0.1525 \\
\hline E1 & 0.1387 & 0.0083 & 0.5175 & 0.5175 & 0.0145 & 0.0145 & 0.1925 & 0.2028 & 0.1759 & 0.2277 & 0.1263 & 0.5175 & 0.0000 \\
\hline E2 & 0.1416 & 0.0028 & 0.3965 & 0.3965 & 0.0028 & 0.0028 & 0.0085 & 0.0085 & 0.0057 & 0.0085 & 0.0057 & & 0.0000 \\
\hline E3 & 0.3441 & 0.1350 & 0.4632 & 0.4632 & 0.0311 & 0.0311 & 0.1251 & 0.1310 & 0.1138 & 0.1588 & 0.0814 & 0.5956 & 0.0000 \\
\hline E4 & 0.0000 & 0.0080 & 0.0160 & 0.0160 & 0.0016 & 0.0016 & 0.0008 & 0.0008 & 0.0008 & 0.0016 & 0.0008 & 0.9997 & 0.0000 \\
\hline E5 & 0.0000 & 0.0644 & 0.2578 & 0.2578 & 0.0322 & 0.0322 & 0.4060 & 0.4318 & 0.3738 & 0.4833 & 0.2642 & 0.2578 & 0.0000 \\
\hline E6 & 0.8002 & 0.5345 & 0.0000 & 0.0000 & 0.0281 & 0.0281 & 0.1242 & 0.1296 & 0.1134 & 0.1447 & 0.0799 & 0.0000 & 0.0000 \\
\hline F1 & 0.2767 & 0.1737 & 0.2445 & 0.2896 & 0.0837 & 0.0644 & 0.4440 & 0.2960 & 0.4569 & 0.4311 & 0.0772 & 0.1351 & 0.1866 \\
\hline F2 & 0.1179 & 0.1088 & 0.0997 & 0.1723 & 0.0997 & 0.0997 & 0.3627 & 0.3627 & 0.6801 & 0.4171 & 0.0453 & 0.0363 & 0.1088 \\
\hline F3 & 0.0000 & 0.2489 & 0.7467 & 0.0000 & 0.3734 & 0.3734 & 0.0000 & 0.0000 & 0.0000 & 0.2489 & 0.0000 & 0.1991 & 0.0000 \\
\hline F4 & 0.3558 & 0.3558 & 0.6089 & 0.5062 & 0.3045 & 0.1027 & 0.0000 & 0.0000 & 0.0000 & 0.0000 & 0.0000 & 0.0000 & 0.1284 \\
\hline F5 & 0.1877 & 0.1953 & 0.3839 & 0.4512 & 0.0406 & 0.0494 & 0.3343 & 0.3861 & 0.3084 & 0.4034 & 0.1613 & 0.1556 & 0.0526 \\
\hline F6 & 0.1887 & 0.1402 & 0.1914 & 0.1914 & 0.3517 & 0.3517 & 0.3504 & 0.3504 & 0.3504 & 0.3504 & 0.3504 & 0.1011 & 0.0000 \\
\hline F7 & 1.0000 & 1.0000 & 1.0000 & 1.0000 & 1.0000 & 1.0000 & 0.4365 & 0.5492 & 0.3077 & 1.0000 & 1.0000 & 1.0000 & 1.0000 \\
\hline
\end{tabular}


Table A4. Enhanced normalized matrix.

\begin{tabular}{|c|c|c|c|c|c|c|c|c|c|c|c|c|c|}
\hline Enhanced & H1 & H2 & H3 & H4 & H5 & H6 & H7 & H8 & H9 & H10 & H11 & H12 & H13 \\
\hline $\mathrm{T} 1$ & 9043 & 9043 & 0.9043 & 0.9043 & 0.9043 & 0.9043 & 0.9043 & 0.9043 & 0.9043 & 0.9043 & 0.9787 & 0.9787 & 1.0000 \\
\hline $\mathrm{T} 2$ & 0.9065 & 0.9065 & 0.9065 & 0.9065 & 0.9065 & 0.9065 & 0.9065 & 0.9065 & 0.9065 & 0.9065 & 1.0000 & 1.0000 & 0.9346 \\
\hline T3 & 0.9660 & 0.9612 & 0.9709 & 0.9709 & 0.9612 & 0.9612 & 0.8544 & 0.8641 & 0.8398 & 0.9029 & 0.7718 & 0.9757 & 1.0000 \\
\hline $\mathrm{T} 4$ & 0.9175 & 0.9175 & 0.9175 & 0.9175 & 0.8660 & 0.8660 & 0.9588 & 1.0000 & 0.9175 & 0.9381 & 1.0000 & 0.9175 & 0.8660 \\
\hline $\mathrm{T} 5$ & 0.9077 & 0.9077 & 0.9385 & 1.0000 & 0.9077 & 0.9077 & 0.9077 & 0.9077 & 0.9077 & 0.9077 & 0.9077 & 0.9846 & 0.9077 \\
\hline T6 & 0.9178 & 0.9178 & 0.9178 & 0.9178 & 0.8618 & 0.8618 & 0.9507 & 1.0000 & 0.9178 & 0.9441 & 0.9901 & 0.9408 & 0.8618 \\
\hline E1 & 0.9070 & 0.8750 & 1.0000 & 1.0000 & 0.8765 & 0.8765 & 0.9202 & 0.9228 & 0.9162 & 0.9289 & 0.9040 & 1.0000 & 0.8730 \\
\hline E2 & 0.9235 & 0.9077 & 0.9524 & 0.9524 & 0.9077 & 0.9077 & 0.9084 & 0.9084 & 0.9080 & 0.9084 & 0.9080 & 1.0000 & 0.9074 \\
\hline E3 & 0.9504 & 0.9091 & 0.9739 & 0.9739 & 0.8886 & 0.8886 & 0.9072 & 0.9084 & 0.9050 & 0.9138 & 0.8986 & 1.0000 & 0.8825 \\
\hline E4 & 0.9163 & 0.9170 & 0.9177 & 0.9177 & 0.9165 & 0.9165 & 0.9164 & 0.9164 & 0.9164 & 0.9165 & 0.9164 & 1.0000 & 0.9163 \\
\hline E5 & 0.8588 & 0.8776 & 0.9341 & 0.9341 & 0.8682 & 0.8682 & 0.9774 & 0.9849 & 0.9680 & 1.0000 & 0.9360 & 0.9341 & 0.8588 \\
\hline E6 & 1.0000 & 0.9684 & 0.9050 & 0.9050 & 0.9083 & 0.9083 & 0.9197 & 0.9204 & 0.9184 & 0.9221 & 0.9145 & 0.9050 & 0.9050 \\
\hline $\mathrm{F} 1$ & 0.9352 & 0.8981 & 0.9236 & 0.9398 & 0.8657 & 0.8588 & 0.9954 & 0.9421 & 1.0000 & 0.9907 & 0.8634 & 0.8843 & 0.9028 \\
\hline $\mathrm{F} 2$ & 0.9083 & 0.9068 & 0.9053 & 0.9172 & 0.9053 & 0.9053 & 0.9482 & 0.9482 & 1.0000 & 0.9571 & 0.8964 & 0.8950 & 0.9068 \\
\hline F3 & 0.9007 & 0.9338 & 1.0000 & 0.9007 & 0.9503 & 0.9503 & 0.9007 & 0.9007 & 0.9007 & 0.9338 & 0.9007 & 0.9272 & 0.9007 \\
\hline F4 & 0.9544 & 0.9544 & 1.0000 & 0.9815 & 0.9452 & 0.9089 & 0.8904 & 0.8904 & 0.8904 & 0.8904 & 0.8904 & 0.8904 & 0.9135 \\
\hline F5 & 0.9044 & 0.9071 & 0.9756 & 1.0000 & 0.8510 & 0.8542 & 0.9576 & 0.9764 & 0.9482 & 0.9827 & 0.8948 & 0.8928 & 0.8554 \\
\hline F6 & 0.8750 & 0.8378 & 0.8771 & 0.8771 & 1.0000 & 1.0000 & 0.9990 & 0.9990 & 0.9990 & 0.9990 & 0.9990 & 0.8079 & 0.7304 \\
\hline F7 & 1.0000 & 1.0000 & 1.0000 & 1.0000 & 1.0000 & 1.0000 & 0.6698 & 0.7358 & 0.5943 & 1.0000 & 1.0000 & 1.0000 & 1.0000 \\
\hline
\end{tabular}

Table A5. The 48 MCDM ranking results.

\begin{tabular}{|c|c|c|c|c|c|c|c|c|c|c|c|c|c|c|c|}
\hline Weighting & Evaluation & Normalization & H1 & $\mathrm{H} 2$ & H3 & H4 & H5 & H6 & H7 & H8 & H9 & H10 & H11 & H12 & H13 \\
\hline Mean & TOPSIS & MinMax & 7 & 4 & 12 & 11 & 3 & 1 & 6 & 9 & 5 & 10 & 8 & 13 & 2 \\
\hline Mean & TOPSIS & Max & 9 & 4 & 12 & 11 & 3 & 2 & 5 & 7 & 6 & 10 & 8 & 13 & 1 \\
\hline Mean & TOPSIS & Vector & 10 & 8 & 12 & 11 & 7 & 5 & 1 & 4 & 6 & 9 & 3 & 13 & 2 \\
\hline Mean & TOPSIS & Enhanced & 9 & 4 & 11 & 12 & 2 & 1 & 3 & 5 & 6 & 7 & 10 & 13 & 8 \\
\hline Mean & VIKOR & MinMax & 7 & 5 & 12 & 11 & 4 & 2 & 1 & 9 & 6 & 10 & 8 & 13 & 3 \\
\hline Mean & VIKOR & Max & 7 & 5 & 12 & 11 & 4 & 2 & 1 & 9 & 6 & 10 & 8 & 13 & 3 \\
\hline Mean & VIKOR & Vector & 7 & 5 & 12 & 11 & 4 & 2 & 1 & 9 & 6 & 10 & 8 & 13 & 3 \\
\hline Mean & VIKOR & Enhanced & 7 & 5 & 12 & 11 & 4 & 2 & 1 & 9 & 6 & 10 & 8 & 13 & 3 \\
\hline Entropy & TOPSIS & MinMax & 8 & 6 & 12 & 11 & 7 & 5 & 3 & 4 & 2 & 10 & 9 & 13 & 1 \\
\hline Entropy & TOPSIS & Max & 8 & 6 & 12 & 11 & 7 & 5 & 3 & 4 & 2 & 10 & 9 & 13 & 1 \\
\hline Entropy & TOPSIS & Vector & 10 & 9 & 12 & 11 & 7 & 5 & 2 & 3 & 1 & 8 & 6 & 13 & 4 \\
\hline Entropy & TOPSIS & Enhanced & 10 & 8 & 11 & 12 & 6 & 5 & 3 & 4 & 2 & 7 & 9 & 13 & 1 \\
\hline Entropy & VIKOR & MinMax & 9 & 7 & 12 & 11 & 6 & 5 & 2 & 3 & 1 & 10 & 8 & 13 & 4 \\
\hline Entropy & VIKOR & Max & 9 & 7 & 12 & 11 & 6 & 5 & 2 & 3 & 1 & 10 & 8 & 13 & 4 \\
\hline Entropy & VIKOR & Vector & 9 & 7 & 12 & 11 & 6 & 5 & 2 & 3 & 1 & 10 & 8 & 13 & 4 \\
\hline Entropy & VIKOR & Enhanced & 9 & 7 & 12 & 11 & 6 & 5 & 2 & 3 & 1 & 10 & 8 & 13 & 4 \\
\hline Std & TOPSIS & MinMax & 6 & 5 & 12 & 13 & 2 & 3 & 9 & 10 & 8 & 11 & 4 & 7 & 1 \\
\hline Std & TOPSIS & Max & 6 & 5 & 12 & 13 & 2 & 3 & 9 & 10 & 8 & 11 & 4 & 7 & 1 \\
\hline Std & TOPSIS & Vector & 6 & 5 & 12 & 13 & 3 & 2 & 8 & 10 & 7 & 11 & 4 & 9 & 1 \\
\hline Std & TOPSIS & Enhanced & 6 & 5 & 11 & 12 & 3 & 2 & 8 & 9 & 7 & 10 & 4 & 13 & 1 \\
\hline Std & VIKOR & MinMax & 6 & 5 & 12 & 13 & 2 & 3 & 9 & 10 & 8 & 11 & 4 & 7 & 1 \\
\hline Std & VIKOR & Max & 6 & 5 & 12 & 13 & 2 & 3 & 9 & 10 & 8 & 11 & 4 & 7 & 1 \\
\hline Std & VIKOR & Vector & 6 & 5 & 12 & 13 & 2 & 3 & 9 & 10 & 8 & 11 & 4 & 7 & 1 \\
\hline Std & VIKOR & Enhanced & 6 & 5 & 12 & 13 & 2 & 3 & 9 & 10 & 8 & 11 & 4 & 7 & 1 \\
\hline CRITIC & TOPSIS & MinMax & 7 & 4 & 12 & 11 & 3 & 1 & 6 & 8 & 5 & 9 & 10 & 13 & 2 \\
\hline CRITIC & TOPSIS & $\operatorname{Max}$ & 8 & 6 & 12 & 11 & 3 & 2 & 5 & 7 & 4 & 10 & 9 & 13 & 1 \\
\hline CRITIC & TOPSIS & Vector & 10 & 8 & 12 & 11 & 7 & 6 & 1 & 3 & 2 & 9 & 5 & 13 & 4 \\
\hline CRITIC & TOPSIS & Enhanced & 9 & 7 & 10 & 12 & 2 & 1 & 3 & 5 & 4 & 6 & 11 & 13 & 8 \\
\hline CRITIC & VIKOR & MinMax & 7 & 5 & 10 & 9 & 3 & 1 & 6 & 12 & 4 & 8 & 13 & 11 & 2 \\
\hline CRITIC & VIKOR & Max & 7 & 5 & 10 & 9 & 3 & 1 & 6 & 12 & 4 & 8 & 13 & 11 & 2 \\
\hline CRITIC & VIKOR & Vector & 7 & 5 & 10 & 9 & 3 & 1 & 6 & 12 & 4 & 8 & 13 & 11 & 2 \\
\hline CRITIC & VIKOR & Enhanced & 7 & 5 & 10 & 9 & 3 & 1 & 6 & 12 & 4 & 8 & 13 & 11 & 2 \\
\hline Angle & TOPSIS & MinMax & 10 & 8 & 12 & 11 & 7 & 5 & 1 & 3 & 2 & 9 & 6 & 13 & 4 \\
\hline Angle & TOPSIS & Max & 10 & 8 & 12 & 11 & 7 & 6 & 1 & 3 & 2 & 9 & 5 & 13 & 4 \\
\hline Angle & TOPSIS & Vector & 10 & 9 & 12 & 11 & 7 & 6 & 1 & 2 & 3 & 8 & 4 & 13 & 5 \\
\hline Angle & TOPSIS & Enhanced & 10 & 9 & 11 & 12 & 5 & 1 & 2 & 4 & 7 & 8 & 6 & 13 & 3 \\
\hline
\end{tabular}


Table A5. Cont.

\begin{tabular}{cccccccccccccccc}
\hline Weighting & Evaluation & Normalization & H1 & H2 & H3 & H4 & H5 & H6 & H7 & H8 & H9 & H10 & H11 & H12 & H13 \\
\hline Angle & VIKOR & MinMax & 9 & 8 & 11 & 12 & 6 & 5 & 1 & 2 & 3 & 10 & 7 & 13 & 4 \\
Angle & VIKOR & Max & 9 & 8 & 11 & 12 & 6 & 5 & 1 & 2 & 3 & 10 & 7 & 13 & 4 \\
Angle & VIKOR & Vector & 9 & 8 & 11 & 12 & 6 & 5 & 1 & 2 & 3 & 10 & 7 & 13 & 4 \\
Angle & VIKOR & Enhanced & 9 & 8 & 11 & 12 & 6 & 5 & 1 & 2 & 3 & 10 & 7 & 13 & 4 \\
Gini & TOPSIS & MinMax & 10 & 8 & 11 & 12 & 7 & 6 & 1 & 3 & 2 & 9 & 5 & 13 & 4 \\
Gini & TOPSIS & Max & 10 & 8 & 12 & 11 & 7 & 6 & 1 & 3 & 2 & 9 & 5 & 13 & 4 \\
Gini & TOPSIS & Vector & 10 & 9 & 11 & 12 & 7 & 6 & 1 & 3 & 2 & 8 & 4 & 13 & 5 \\
Gini & TOPSIS & Enhanced & 10 & 9 & 11 & 12 & 7 & 5 & 2 & 3 & 6 & 8 & 4 & 13 & 1 \\
Gini & VIKOR & MinMax & 9 & 8 & 11 & 12 & 6 & 5 & 1 & 2 & 3 & 10 & 7 & 13 & 4 \\
Gini & VIKOR & Max & 9 & 8 & 11 & 12 & 6 & 5 & 1 & 2 & 3 & 10 & 7 & 13 & 4 \\
Gini & VIKOR & Vector & 9 & 8 & 11 & 12 & 6 & 5 & 1 & 2 & 3 & 10 & 7 & 13 & 4 \\
Gini & VIKOR & Enhanced & 9 & 8 & 11 & 12 & 6 & 5 & 1 & 2 & 3 & 10 & 7 & 13 & 4 \\
\hline
\end{tabular}

\section{References}

1. IPCC. Summary for Policymakers. In Global Warming of $1.5^{\circ} \mathrm{C}$. An IPCC Special Report on the Impacts of Global Warming of $1.5^{\circ} \mathrm{C}$ Above Pre-Industrial Levels and Related Global Greenhouse Gas Emission Pathways, in the Context of Strengthening the Global Response to the Threat of Climate Change, Sustainable Development, and Efforts to Eradicate Poverty; Masson-Delmotte, V., Zhai, P., Pörtner, H.-O., Roberts, D., Skea, J., Shukla, P.R., Pirani, A., Moufouma-Okia, W., Péan, C., Pidcock, R., et al., Eds.; World Meteorological Organization: Geneva, Switzerland, 2018; 32p.

2. Ramaswami, A.; Tong, K.; Canadell, J.G.; Jackson, R.B.; Stokes, E.; Dhakal, S.; Finch, M.; Jittrapirom, P.; Singh, N.; Yamagata, Y.; et al. Carbon Analytics for Net-Zero Emissions Sustainable Cities. Nat. Sustain. 2021, 4, 460-463. [CrossRef]

3. Salvia, M.; Reckien, D.; Pietrapertosa, F.; Eckersley, P.; Spyridaki, N.A.; Krook-Riekkola, A.; Olazabal, M.; Hurtado, S.D.G.; Simoes, S.G.; Geneletti, D.; et al. Will Climate Mitigation Ambitions Lead to Carbon Neutrality? An Analysis of the Local-Level Plans of 327 Cities in the EU. Renew. Sustain. Energy Rev. 2021, 135, 110253. [CrossRef]

4. Esteves, G.R.T.; Bastos, B.Q.; Cyrino, F.L.; Calili, R.F.; Souza, R.C. Long Term Electricity Forecast: A Systematic Review. Procedia Computer Science. 2015, 55, 549-558. [CrossRef]

5. International Energy Agency. World Energy Investment 2020; IEA: Paris, France, 2020; Available online: https://www.iea.org/ reports / world-energy-investment-2020 (accessed on 29 August 2021).

6. The Danish Government. Folketinget Klimaaftale for Energi Og Industr mv. 2020. 2020. Available online: https://fm.dk/media/ 18085/klimaaftale-for-energi-og-industri-mv-2020.pdf (accessed on 29 August 2021).

7. The Danish Government. Klimaplan for en Grøn Affaldssektor og Cirkulær Økonomi. 2020. Available online: https://www. regeringen.dk/media/9591/aftaletekst.pdf (accessed on 29 August 2021).

8. Martinopoulos, G.; Papakostas, K.T.; Papadopoulos, A.M. A Comparative Review of Heating Systems in EU Countries, Based on Efficiency and Fuel Cost. Renew. Sustain. Energy Rev. 2018, 90, 687-699. [CrossRef]

9. Sayegh, M.A.; Jadwiszczak, P.; Axcell, B.P.; Niemierka, E.; Bryś, K.; Jouhara, H. Heat Pump Placement, Connection and Operational Modes in European District Heating. Energy Build. 2018, 166, 122-144. [CrossRef]

10. Mahmoud, M.; Ramadan, M.; Naher, S.; Pullen, K.; Olabi, A.G. The Impacts of Different Heating Systems on the Environment: A Review. Sci. Total Environ. 2021, 766, 142625. [CrossRef]

11. Li, X.; Lyu, W.; Ran, S.; Wang, B.; Wu, W.; Yang, Z.; Jiang, S.; Cui, M.; Song, P.; You, T.; et al. Combination Principle of Hybrid Sources and Three Typical Types of Hybrid Source Heat Pumps for Year-Round Efficient Operation. Energy 2020, $193,116772$. [CrossRef]

12. Mäki, E.; Kannari, L.; Hannula, I.; Shemeikka, J. Decarbonization of a District Heating System with a Combination of Solar Heat and Bioenergy: A Techno-Economic Case Study in the Northern European Context. Renew. Energy 2021, 175, 1174-1199. [CrossRef]

13. Adfærdsanalyse af evidas kunder udarbejdet af/kl.7. Gaskundernes forventninger til deres fremtidige opvarmning. 2021. Available online: https:/ /ipaper.ipapercms.dk/HMNNaturgas/evida/analysegaskundernes-forventninger-til-deres-fremtidigeopvarmning (accessed on 29 August 2021).

14. Siksnelyte, I.; Zavadskas, E.K.; Streimikiene, D.; Sharma, D. An Overview of Multi-Criteria Decision-Making Methods in Dealing with Sustainable Energy Development Issues. Energies 2018, 11, 2754. [CrossRef]

15. Stojčić, M.; Zavadskas, E.K.; Pamučar, D.; Stević, Ž.; Mardani, A. Application of MCDM Methods in Sustainability Engineering: A Literature Review 2008-2018. Symmetry 2019, 11, 350. [CrossRef]

16. Siksnelyte-Butkiene, I.; Zavadskas, E.K.; Streimikiene, D. Multi-Criteria Decision-Making (MCDM) for the Assessment of Renewable Energy Technologies in a Household: A Review. Energies 2020, 13, 1164. [CrossRef]

17. Janssen, R. On the Use of Multi-Criteria Analysis in Environmental Impact Assessment in The Netherlands. J. Multi-Criteria Decis. Anal. 2001, 10, 101-109. [CrossRef] 
18. Zhang, C.; Wang, Q.; Zeng, S.; Baležentis, T.; Štreimikienė, D.; Ališauskaitè-Šeškienė, I.; Chen, X. Probabilistic Multi-Criteria Assessment of Renewable Micro-Generationtechnologies in Households. J. Clean. Prod. 2019, 212, 582-592. [CrossRef]

19. Wimmler, C.; Hejazi, G.; de Fernandes, E.O.; Moreira, C.; Connors, S. Multi-Criteria Decision Support Methods for Renewable Energy Systems on Islands. J. Clean Energy Technol. 2015, 3, 185-195. [CrossRef]

20. Rigo, P.D.; Rediske, G.; Rosa, C.B.; Gastaldo, N.G.; Michels, L.; Júnior, A.L.N.; Siluk, J.C.M. Renewable Energy Problems: Exploring the Methods to Support the Decision-Making Process. Sustainability 2020, 12, 10195. [CrossRef]

21. Mardani, A.; Jusoh, A.; Zavadskas, E.K.; Cavallaro, F.; Khalifah, Z. Sustainable and Renewable Energy: An Overview of the Application of Multiple Criteria Decision Making Techniques and Approaches. Sustainability 2003, 7, 13947-13984. [CrossRef]

22. Hadian, S.; Madani, K. A System of Systems Approach to Energy Sustainability Assessment: Are All Renewables Really Green? Ecol. Indic. 2015, 52, 194-206. [CrossRef]

23. Sagi, O.; Rokach, L. Ensemble Learning: A Survey. Wiley Interdiscip. Rev. Data Min. Knowl. Discov. 2018, 8, e1249. [CrossRef]

24. Aytekin, A. Comparative Analysis of the Normalization Techniques in the Context of MCDM Problems. Decis. Mak. Appl. Manag. Eng. 2021, 4, 1-25. [CrossRef]

25. Odu, G.O. Weighting Methods for Multi-Criteria Decision Making Technique. J. Appl. Sci. Environ. Manag. 2019, 23, 1449-1457. [CrossRef]

26. Urošević, K.; Gligorić, Z.; Miljanović, I.; Beljić, Č.; Gligorić, M. Novel Methods in Multiple Criteria Decision-Making Process (MCRAT and RAPS)-Application in the Mining Industry. Mathematics 2021, 9, 1980. [CrossRef]

27. Opricovic, S.; Tzeng, G.H. Compromise Solution by MCDM Methods: A Comparative Analysis of VIKOR and TOPSIS. Eur. J. Oper. Res. 2004, 156, 445-455. [CrossRef]

28. Mon, D.L.; Cheng, C.H. Fuzzy System Reliability Analysis for Components with Different Membership Functions. Fuzzy Sets Syst. 1994, 64, 145-157. [CrossRef]

29. Danish Energy Agency. Technology Data for Heating Installations Guideline; Danish Energy Agency: København, Denmark, 2021; Available online: https://ens.dk/sites/ens.dk/files/Analyser/technology_data_catalogue_for_individual_heating_installations. pdf (accessed on 29 August 2021).

30. Varmepumper I Energistyrelsen. Available online: https:/ /sparenergi.dk/forbruger/varme/varmepumper (accessed on 29 August 2021).

31. Samfundsoekonomiske_beregningsforudsaetninger_for_energipriser_og_emissioner_2019. Available online: https://ens.dk/ sites/ens.dk/files / Analyser/samfundsoekonomiske_beregningsforudsaetninger_for_energipriser_og_emissioner_2019.pdf (accessed on 29 August 2021).

32. Data, Tabeller, Statistikker Og Kort Energistatistik 2019. Available online: https://ens.dk/sites/ens.dk/files/Statistik/ energistatistik2019_dk-webtilg.pdf (accessed on 29 August 2021).

33. Energi- $\mathrm{Og} \mathrm{CO}$-Regnskabet I Energistyrelsen. Available online: https://sparenergi.dk/offentlig/vaerktoejer/energi-og-co2 -regnskabet (accessed on 29 August 2021).

34. Energimærkning Boliger I Energistyrelsen. Available online: https://sparenergi.dk/forbruger/boligen/energimaerkning-boliger (accessed on 29 August 2021).

35. Bekendtgørelse Om Tilskud Til Energibesparelser Og Energieffektiviseringer i Bygninger Til Helårsbeboelse. Available online: https:/ / www.retsinformation.dk/eli/lta/2021/525\#id26bbf930-5196-4240-810d-f94df9dbc0ff (accessed on 29 August 2021).

36. Shekhovtsov, A.; Salabun, W. A Comparative Case Study of the VIKOR and TOPSIS Rankings Similarity. Procedia Comput. Sci. 2020, 176, 3730-3740. [CrossRef]

37. Chang, J.-F.; Lai, C.-J.; Wang, C.-N.; Hsueh, M.-H.; Nguyen, V.T. Mathematics Fuzzy Optimization Model for Decision-Making in Supply Chain Management. Mathematics 2021, 9, 312. [CrossRef]

38. Yang, Y.; Ren, J.; Solgaard, H.S.; Xu, D.; Nguyen, T.T. Using Multi-criteria Analysis to Prioritize Renewable Energy Home Heating Technologies. Sustain. Energy Technol. Assess. 2018, 29, 36-43. [CrossRef] 